NBER WORKING PAPER SERIES

\title{
THE FINANCING OF LOCAL GOVERNMENT IN CHINA: STIMULUS LOAN WANES AND SHADOW BANKING WAXES
}

\author{
Zhuo Chen \\ Zhiguo He \\ Chun Liu \\ Working Paper 23598 \\ http://www.nber.org/papers/w23598 \\ NATIONAL BUREAU OF ECONOMIC RESEARCH \\ 1050 Massachusetts Avenue \\ Cambridge, MA 02138 \\ July 2017, Revised October 2018
}

We thank Chong-En Bai, Jennifer Carpenter, Will Cong, Haoyu Gao, Kinda Hachem, Chang-tai Hsieh, Zheng Liu, Jacopo Ponticelli, Zheng Michael Song, Jun Qian, Nancy Qian, Hong Ru, Rengming Xie, Zhishu Yang, and participants at the 2016 Nankai University School of Finance Annual Conference, Shanghai University of Finance and Economics, Central University of Finance and Economics School of Finance, Renmin University of China Hanqing Institute, Chinese University of Hong Kong (Shenzhen), 2017 NBER Chinese Economy working group (Boston meeting), the 2nd IMF-Atlanta Fed Research Workshop on China's Economy, and 2017 Asian Bureau of Finance and Economic Research Conference, the 2nd China Financial Research Conference, 2017 China International Conference in Finance, 2017 Summer Institute of Finance Conference, and 2017 HKUST Finance Symposium for helpful comments. We thank Yunjun Yu and Yilin Zhang for providing more recent issuance purpose data of municipal corporate bonds, and Chen gratefully acknowledges the support from Minsheng Wealth Management Research Center at Tsinghua University. The views expressed herein are those of the authors and do not necessarily reflect the views of the National Bureau of Economic Research.

NBER working papers are circulated for discussion and comment purposes. They have not been peer-reviewed or been subject to the review by the NBER Board of Directors that accompanies official NBER publications.

(C) 2017 by Zhuo Chen, Zhiguo He, and Chun Liu. All rights reserved. Short sections of text, not to exceed two paragraphs, may be quoted without explicit permission provided that full credit, including $\odot$ notice, is given to the source. 
The Financing of Local Government in China: Stimulus Loan Wanes and Shadow Banking Waxes

Zhuo Chen, Zhiguo He, and Chun Liu

NBER Working Paper No. 23598

July 2017, Revised October 2018

JEL No. F62,F63,G23,O16,O17,O53

\section{ABSTRACT}

China's four-trillion-yuan stimulus package fueled by bank loans in 2009 has led to the rapid growth of shadow banking activities after 2012. Local governments financed the stimulus through bank loans in 2009, and resorted to non-bank debt financing after 2012 given the rollover pressure from bank debt coming due, a manifestation of the stimulus-loan-hangover effect. Crosssectionally, provinces with greater bank loan growth in 2009 experienced more Municipal Corporate Bonds issuance during 2012-2015, together with more shadow banking activities including Entrusted loans and Wealth Management Products. We highlight the market forces behind the regulation changes on local government debt post 2012.

Zhuo Chen

Tsinghua University

43 Chengfu Road

Beijing, 100083

China

chenzh@pbcsf.tsinghua.edu.cn

Zhiguo He

University of Chicago

Booth School of Business

5807 S. Woodlawn Avenue

Chicago, IL 60637

and NBER

zhiguo.he@chicagobooth.edu
Chun Liu

School of Economics and Management

Tsinghua University

liuch@sem.tsinghua.edu.cn

A is available at https://drive.google.com/file/d/0Bxk_O0Tjcokja1hZdTV5NXFhWVU/view 


\section{Introduction}

Right after the 2007/08 global financial crisis hit the export-driven Chinese economy heavily, the State Council of China announced the four-trillion-yuan plan in November 2008 to stimulate China's economy to maintain its "usual" above-9\% annual growth rate. Bai et al. (2016) document that most of the stimulus package was implemented through China's local governments that finance the infrastructure investment by bank loans via the off-balance-sheet local government financing vehicles (LGFVs thereafter). Although this aggressive plan helped bolster the slumping Chinese economy, the resulting swelling local government debt in China caught the wide attention of scholars and practitioners all over the world. About five years later, more and more studies had emerged on the unintended consequences of the 2009 stimulus package on the growth of China's economy post 2009.

We argue that one of these unintended consequences is the unprecedented rapid growth of shadow banking activities in China after 2012. The origination of shadow banking in China around 2008 can be attributed to other reasons (e.g., Hachem and Song $(2017 a, b))$. However, China's shadow banking activities have experienced unprecedented accelerated growth after 2012; for instance, Wealth Management Products (WMPs), a widely used tool to attract off-balance-sheet deposits by commercial banks in China, grew by a total of RMB 3.5 trillion during the three-year period from 2008 to 2011 but increased by RMB 2.5 (3.1) trillion in a single year in 2012 (2013).

By focusing on the composition shift of the liability side of China's local governments since 2009, this paper shows the stimulus-loan-hangover effect pushed them toward nonbank debt financing after 2012. The stimulus-loan-hangover effects include the financing demand to continue the long-term infrastructure projects started in 2009, as well as the rollover pressure of maturing bank loans that were taken on by LGFVs at that time. These forces fostered the rapid growth of shadow banking activities after 2012, and most of these non-bank debt financing sources are related to Trust loans and/or WMPs, two off-balance-sheet items that are often regarded as the barometers of the shadow banking activities in China.

We started by explaining the background of the 2009 four-trillion-yuan stimulus package and its connections to local governments in China. Due to the public-goods nature of the infrastructure-centric stimulus package, local governments carried out the four-trillion-yuan expansion in 2009. However, according to the 1994 budget law, local governments are not allowed to borrow. To facilitate and expedite the stimulus plan, Beijing explicitly encouraged municipals to borrow from banks through their LGFVs, an 
important group of state-owned enterprises (SOEs) in China. As planned, bank loans and investment soared in 2009, but municipals were left with mounting bank debt.

Facing the rising warnings of local government debt, starting in the second half of 2010, Beijing reverted its ultra-expansive credit policy back to its normal level, and the National Audit Office (NAO) conducted two comprehensive surveys on local government debt. These two official reports, dated December 2010 and June 2013, are the most authoritative documents that shape all discussions on this topic. Based on the mid-2013 report, we focus on four different categories of debt that are sitting on the liability side of local governments: Bank loans, Munibonds, Municipal Corporate Bonds, and Trust loans, with the latter three types being non-bank debts.

Our paper focuses on the third type of debt, namely, Municipal Corporate Bonds (MCBs hereafter). ${ }^{1}$ These bonds are issued by LGFVs, and hence are corporate bonds legally; but of course they have implicit guarantees from corresponding local governments, and hence enjoy the extra safety of municipal bonds. These bail-out expectations, especially for LGFVs that are both SOEs and backed by local governments, are widely spread and particularly relevant in China. ${ }^{2}$

We highlight that our study treats the corporate bonds sector as an integrated part of the shadow banking system in China. ${ }^{3}$ Although corporate bonds, which include MCBs issued by LGFVs, are commonly viewed as standard and transparent financial market instruments in China, they were heavily purchased by WMPs, which are the most important component of Chinese shadow banking activities. Put simply, a majority of the Chinese corproate bond sector is funded by shadow banking. According to recent studies based on regulatory data (Ehlers et al. (2018); Lei et al. (2018)), around 40\% of

\footnotetext{
${ }^{1}$ It is "Cheng-Tou-Zhai" in Chinese, or "city investment bonds" by a literal word-for-word translation. We adopt "Municipal Corporate Bond" from the English translation the "Cheng-Tou-Zhai" index provided by the China Securities Index Company Limited (CSI), which is the leading index provider in China (e.g., CSI300 index) and is jointly owned by the Shenzhen Stock Exchange and the Shanghai Stock Exchange. In the literature, papers have been using different translations; for instance, local government bonds by Huang et al. (2016), Chengtou bonds by Ang et al. (2017), and urban construction and investment bonds by Gao et al. (2018). Some practitioners' articles also use the term LGFV bond.

${ }^{2}$ Up to August 2017, no single case of MCB default has occurred yet. On the other hand, Chinese investors have started to embrace the default risk on corporate bonds. Because of the slowdown of the Chinese economy in the last five years, firms-whether privately owned or state owned-started to default sporadically in 2014, and in 201634 firms defaulted on their bonds in China's corporate bond market. However, local governments are still heavily involved in bankruptcy resolutions, because many defaulting enterprises have strong ties to local governments.

${ }^{3}$ The literature typically classifies trust loans (Allen et al. (2017)), entrusted loans (Allen et al. (2018); Chen et al. (2018b); He et al. (2018)), and undiscounted bank acceptance bills (An and Yu (2018)) as shadow banking actitivies as surveyed by Hachem (2018). WMPs are widely referred to as shadow banking activities, but they are not the ultimate users of funds (e.g., WMPs can be invested in trust loans).
} 
corporate bond funding was being channelled by WMPs during 2014, and this number is even higher for MCBs (about 60\%). The linkage between LGFV-issued MCBs and shadow banking activities is widely accpeted among industry practitioners in the Chinese financial market (see Section 4.5.4 for more details with recent regulation changes).

Consistent with the hypothesis of the stimulus-loan-hangover effect, we observe a robust pattern of the composition change of local government debt, that is, a shift from bank loans to non-bank debt obligations over the period of 2008-2016. Our analysis highlights the rollover channel particularly: ${ }^{5}$ following the back-to-normal credit policy after 2009, local governments needed to refinance/rollover their three-to-five-year-maturity bank loans coming due, by non-bank debt sources that include Trust loans and MCBs. Our view of the "stimulus-loan-hangover effect" is also confirmed with the post-2013 rapid growth of Trust loans as reported in "Aggregate Financing to the Real Economy" by China's central bank.

The hypothesis of the stimulus-loan-hangover effect has the following cross-sectional prediction: the areas with more bank-loan-fueled stimulus in 2009, whether demanddriven or supply-driven, should have more MCB issuances several years later as the after-effect of the stimulus package. This prediction is confirmed in the data, a result that is robust at both regional and provincial levels, and with relevant controls (e.g., controlling provincial GDP growth in later years). Section 4.3 further introduces an instrumental variable (IV), namely, whether a provincial governor was in his/her early official term as of 2009, that captures the exogenous "demand" shock to the abnormal stimulus bank loans in 2009. The results of IV estimation provides consistent evidence for the stimulus-loan-hangover causal relation. On the other hand, this hangover effect is alleviated for provinces with more policy-bank loans in 2009, consistent with the fact that policy banks are on average issuing longer-term loans. We further decompose the MCB issuance by purpose, and find that only the repaying-bank-loans component is related to the 2009-stimulus bank loans cross-sectionally, after controlling the provincial economic activities (e.g., GDP growth). In terms of economic magnitude, one more dollar of bank loans in 2009 leads to about 15 cents more MCB issuance to repay bank loans in later years. This estimate implies a loan maturity of about 3.5 years, consistent with Gao et al. (2018) who report that the average LGFV loan maturity is 4.1 years for

\footnotetext{
${ }^{4}$ Interestingly, when regulatory rules on WMPs were tightened after 2017, the corporate bond market also slowed down significantly: the net aggregate social financing from corporate bonds dropped to RMB 0.45 trillion in 2017, in contrast to RMB 3.04 trillion in 2016). See the handbook chapter of Amstad and He (2018) for more details.

${ }^{5}$ The rollover risk emanating from refinancing maturing debt is an active research area in corporate finance, especially after the 2007/08 financial crisis; e.g., Diamond (1991); He and Xiong (2012); Diamond and He (2014).
} 
all loans issued by the largest 19 banks to large LGFVs with an annual credit line of at least RMB 50 million. ${ }^{6}$

Section 4.5 provides evidence linking our findings to China's overall shadow banking activities after 2012. The non-bank local government debt has become increasingly significant relative to shadow banking activities in the overall Chinese economy, rising from $1.5 \%$ in 2008 to $48 \%$ in 2016 . Cross-sectionally, provinces with more bank-loan-fueled stimulus in 2009 experienced more entrusted loan growth during later years. Finally, from publicly available data, by the end of 2016, 62\% (or RMB 4.2 trillion) of MCBs were purchased by WMPs. ${ }^{7}$ We also discuss the connection between Chinese corporate bond markets and shadow banking.

This paper paints a broad picture that links the 2007/08 financial crisis in the U.S., the 2009 four-trillion-yuan stimulus expansion in China, and the surging shadow banking activities in China after 2012. Although both WMPs and Trust loans existed in China's financial markets before 2008, and increased slightly during the period of the 2009 stimulus plan, our perspective helps us understand why these shadow banking activities experienced "barbarous growth" after 2012. In short, the inelastic demand for continuing the long-term infrastructure projects started in 2009, together with the mounting rollover pressure of LGFVs that needed to repay maturing bank loans about four or five years later, played an important role in driving the surging shadow banking activities in China at that time.

We are not saying the stimulus-loan-hangover effect is the only mechanism that explains the rapid development of the Chinese financial market post 2012. In general, China's growth is too sophisticated to be explained by one single force (see literature review for several alternative views). In Concluding Remarks, we argue the stimulusloan hangover has affected the way the government regulated the financial markets in China. For instance, in 2010, the strict enforcement of regulations on LGFV successfully restrained the MCB issuance. But in 2014, facing the mounting rollover pressure, (various) regulators started proposing conflicting rule changes that intentionally facilitated the LGFVs' ability to borrow from the MCB market. This market force, which fundamentally is about how to place traditional banking in a market economy, is perhaps also responsible for the rapid growth of China's interbank market and the expedited process of interest rate liberalization after 2012.

\footnotetext{
${ }^{6}$ Kroeber (2016) also documents that China's localities often take three- to five-year loans to fund decade-long infrastructure projects.

${ }^{7}$ Due to its shortcoming of statistical criteria (e.g., not including WMP investment in some specialpurpose vehicles that can in turn purchase $\mathrm{MCBs}$ ), this number is bound to be an underestimate; one estimate from an anecdotal but trustworthy source is about $70 \%$.
} 
Literature review. This paper belongs to several different yet connected strands of literatures in the recent development of Chinese economy and financial markets. First, our paper analyzes one of the unintended consequences of China's four-trillion-yuan stimulus package in 2009. Bai et al. (2016) offer a comprehensive account of this unprecedented fiscal stimulus package. In contrast to our paper, which focuses on the liability side of the stimulus plan, Bai et al. (2016) emphasize the asset side and its resulting inefficiency. According to Bai et al. (2016), local government may have facilitated access to capital for favored firms and hence worsened the overall efficiency of capital allocation, with a potential permanent decline in the growth rate of China's aggregate productivity and GDP growth. Deng et al. (2015) emphasize the feature of "state control" of the 2009 stimulus package, with state-owned banks extending credit to SOEs and real estate in a massive way. Similarly, based on firm-level data, Cong et al. (2018) document that following the 2009 credit expansion in China, new credit was allocated disproportionately more toward state-owned, low-productivity firms than toward privately owned, high-productivity firms. This finding represents a reversal of the trend observed before 2008 during which capital allocations improved over time (Song et al. (2011)).

Second, the major evidence this paper relies on is MCBs, the corporate bonds issued by LGFVs. Amstad and He (2018) provide an up-to-date overview for the Chinese corporate bond markets. Zhang and Barnett (2014) offer a detailed description of local government debts, especially those taken by LGFVs. Ambrose et al. (2015) study the unique local government financing channel in China by investigating LGFVs' borrowing backed by land sales. Ang et al. (2017) examine the cross-sectional pricing properties of MCBs, emphasizing the role of real estate dependence of the local economy and local political risk associated with the post-2012 anti-corruption campaign. In contrast to Ang et al. (2017), our paper focuses on the quantity of MCBs, and relates its unprecedented growth to the 2009 stimulus plan. ${ }^{8}$

A burgeoning literature studies China's fast-growing shadow banking activities, including both WMPs and entrusted loans. Hachem and Song (2017a) highlight the dif-

\footnotetext{
${ }^{8}$ Liu et al. (2017) find that implicit government gurantee plays an important role in MCB pricing: the local government debt-to-GDP ratio, not LGFV's financial conditions, determines the MCB yield spread. Huang et al. (2016) observe a crowd-out effect of massive public debt issuance on private firms' investment post the four-trillion-yuan stimulus. They argue that such a negative impact is especially severe for firms more dependent on external funding, suggesting the stimulus-driven public debt weakened long-term growth in China. Lastly, Gao et al. (2018) study how the political nexus between local politicians and policy bank officials affects local governments' default decisions on bank loans. Chen et al. (2018a) study the pledgeability effect on asset pricing based on a policy shock on Chinese corporate bond markets.
} 
ferent reactions of the Big-Four banks and their relatively smaller peers facing stricter liquidity regulation rules after 2009, and explain how small and medium-sized banks' regulatory arbitrage triggered by regulation change on liquidity requirement results in shadow banking, tighter interbank markets, and credit growth as unintended consequences. Acharya et al. (2017) show that the stimulus package in 2009 also boosted China's shadow banking activities by analyzing a panel data on WMPs issued by each bank. ${ }^{9}$

\section{Institutional Background}

We briefly describe the background of China's four-trillion-yuan stimulus package in 2009, and its connections to local governments and their financing vehicles. We then move on to document the evolution of the debt assumed by the local governments after 2009.

\subsection{China's Four-Trillion-Yuan Stimulus Plan in 2009}

In the fall of 2008, China's export-driven economy experienced a head-on blow by the 2007/08 financial crisis, which dragged the US economy into the Great Recession. Panel A in Figure 1 shows that China's annualized GDP growth rate dropped from $9.5 \%$ in 2008Q3 to 6.4\% in 2009Q1, as the total export almost more than halved from September 2008 to February 2009. ${ }^{10}$

In response, in November 2008, the Chinese premier Wen Jiabao announced to great fanfare a four-trillion-yuan fiscal stimulus to be spent by 2010, with about RMB 1.5 trillion to be spent on railway, road, airport, water conservancy, and urban power grids; 1 trillion on post-disaster reconstruction (Wenchuan earthquake occurred in May 2008); 1.14 trillion on indemnificatory and comfortable housing, rural livelihood, and infrastructure; and 0.36 trillion on environmental protection and education. As shown in Panel

\footnotetext{
${ }^{9}$ Entrusted loans, referring to the loans between two non-bank parties (e.g., industrial firms) using a bank as an intermediate, are another form of shadow banking that grew rapidly after the 2009 bankloan-fueled stimulus. A couple of recent papers use entrusted loans as the platform to study China's shadow banking system. Chen et al. (2018b) document commercial banks' engagement in intermediating entrusted loans and the various incentives of small and large banks in providing such service. Allen et al. (2018) focus more on the pricing side of entrusted loans and find that entrusted loans between two parties without any relationship charge higher interest rates, potentially to compensate for fundamental and informational risks. Finally, Wang et al. (2016) propose a theoretical framework to understand these shadow banking activities as a part of the "dual-track" interest rate reform, in which WMPs and trust/entrusted loans are ways to channel funds toward more efficient privately-owned firms, but at a higher interest rate than the bank rate offered to state-owned enterprises.

${ }^{10}$ According to the General Administration of Customs of People's Republic of China, the total export drops from 136.7 billion USD in September 2008 to 64.86 billion USD in February 2009.
} 
A of Figure 1, the massive stimulus led to an immediate acceleration in China's GDP growth, which recovered to $11.9 \%$ in 2009Q4 but later slowly landed at $6.7 \%$ in 2016 .

Right after the announcement in November 2008, Dominique Strauss-Kahn, the then managing director of the International Monetary Fund, stated that "it will have an influence not only on the world economy in supporting demand but also a lot of influence on the Chinese economy itself, and I think it is good news for correcting imbalances."11 Indeed, in the short run, many prominent researchers and policymakers believed China's massive fiscal stimulus helped prevent the world recession from deteriorating. ${ }^{12}$ However, less than a decade later, more and more studies have shown the unintended consequences of this vast stimulus package. One of these consequences is the massive debt burden assumed by local governments, which is the focus of our paper.

\subsubsection{Local governments and their financial vehicles}

The stimulus package and the mounting debt burden of local governments in China are just two sides of the same coin. Because the major component of the stimulus package is infrastructure projects, including urban and rural, almost all investment spending is naturally implemented and financed through local governments. Only about 1 trillion out of the 4 trillion comes out of the budget of the central government, implying a financing gap of 3 trillion. ${ }^{13}$ What is more, given the institutional background of national budget law explained below, local governments were not allowed to borrow by themselves at that time, and hence were forced to finance their investment spending via the so-called LGFVs.

Several excellent papers explain the history and peculiarity of the financing of local governments in China. Here, we briefly mention the related institutional details on the regulations faced by local governments and their counter-measures when they are in need of financing. Bai et al. (2016) offer a greater recount of these legal details, and the following exposition is based on their paper.

Before 1994, local governments in China enjoyed considerable freedom in the allocation of local tax revenues. The "tax sharing reform" in 1994 overhauled the budget law and removed control of local governments over local tax revenues. As a result, the tax

\footnotetext{
${ }^{11}$ New York Times, November 9, 2008, "China plans $\$ 586$ billion economic stimulus."

${ }^{12}$ Paul Krugman wrote that China responded by "much more aggressive stimulus than any Western nation - and it has worked out well." See http://krugman.blogs.nytimes.com/2010/07/24/keynes-inasia/.

${ }^{13}$ Still, this inference begs the question of whether China successfully carried out the four-trillion-yuan stimulus package in full over the two years in 2009 and 2010. Numerous articles and sources suggest so; for instance, Bai et al. (2016) show that the gross abnormal investment amount in 2009 and 2010 roughly matches the planned stimulus.
} 
share of local governments fell from about $80 \%$ to $40 \%$ to $50 \%$ in 1994 . Not surprisingly, local governments responded by looking for other sources of revenues. One prominent and controversial channel is land sales, i.e., the seizure by local governments of land from farmers and urban residents and the resale/lease of the land to, say, developers (Zhang and Barnett (2014); Ambrose et al. (2015)). Nevertheless, land sales, which cannot be elevated immediately, are not the major financing source for local governments in implementing the 2009 stimulus package within such a short time.

The 1994 budget law also pushed the LGFVs onto the stage. Although the 1994 budget law made it illegal for local governments to run budget deficits, municipals can run implicit deficits by establishing LGFVs and borrowing against them. Legally, an LGFV is a state-owned enterprise with the corresponding local government as the only or dominant shareholder, with its shares usually held by the State-owned Assets Supervision and Administration Committee (SASAC). Prior to 2009, these LGFVs were severely restricted to limited financing activities.

Things became quite different starting in 2009. To push the stimulus package, the central government decided to circumvent the 1994 budget law. Beijing encouraged local governments to use LGFVs to take on bank loans, which are essentially off-balance-sheet borrowing of local governments. Somewhat interestingly, the central government orchestrated the relaxation of regulation from two directions: the Ministry of Finance, which is in charge of budgetary issues of local governments, and the China Bank Regulation Committee (CBRC), which is in charge of commercial banks in China. On one hand, the Ministry of Finance issued a regulation that allowed local government to finance investment projects using all sources of funds, including budgetary revenue, land revenue, and funds borrowed by local financing vehicles:

"Allowing local government to finance the investment projects by essentially all sources of funds, including budgetary revenue, land revenue and fund borrowed by local financing vehicles." (Document 631, Department of Construction, Ministry of Finance, October 12, 2009)

In the meantime, to encourage banks to extend credit, CBRC made the following public announcement:

"Encourage local governments to attract and to incentivize banking and financial institutions to increase their lending to the investment projects set up by the central government. This can be done by a variety of ways including increasing local fiscal subsidy to interest payment, improving rewarding mechanism for loans and establishing government investment and financing 
platforms compliant with regulations." (Document No. 92, CBRC, March 18, 2009)

Local governments had been keen to promote local economic growth over the past several decades (Li and Zhou (2005)). Given these green lights and, to some extent, explicit encouragement by Beijing, local governments implemented the unprecedented stimulus package through their LGFVs by taking on a massive amount of loans extended by the banking system.
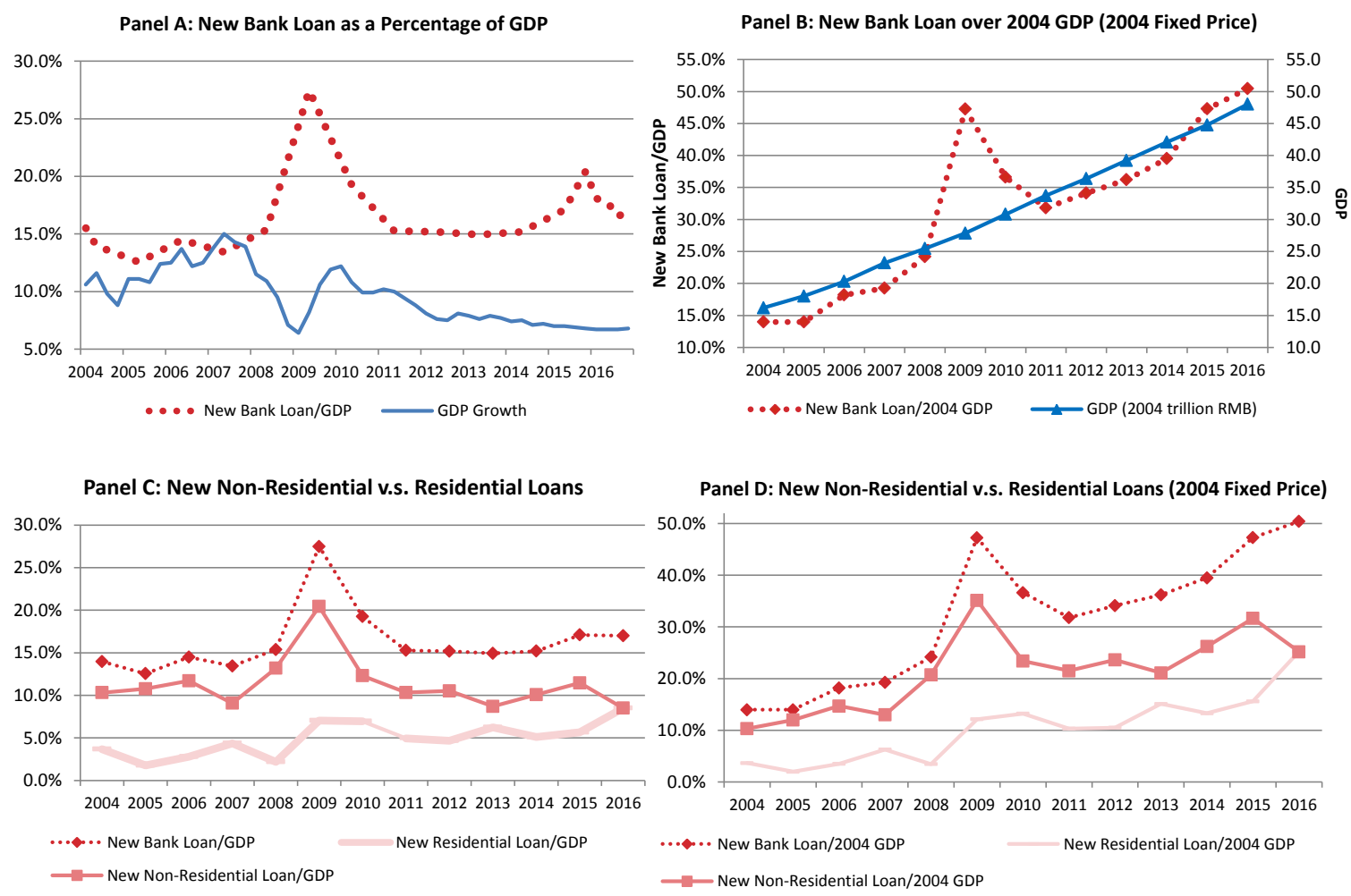

Figure 1: New-Bank-Loan Growth in China, 2004-2016. Panel A plots annual new bank loans over GDP and quarterly GDP growth; Panel B plots new bank loan over 2004 GDP (left scale) and GDP in trillion RMB in 2004 fixed price (right scale); Panel C plots new bank loans, new non-residential bank loans, and new residential bank loans, all over GDP; and Panel D plots new bank loans, new non-residential bank loans, and new residential bank loans, all over 2004 GDP and in 2004 fixed price. Numbers in fixed 2004 price are converted using GDP deflator. Data source: People's Bank of China (bank loans) and China National Bureau of Statistics (GDP and GDP deflator).

\subsubsection{Stimulus package in 2009 fueled by bank loans}

Bai et al. (2016) estimate that about $90 \%$ of local government investment was financed 
via bank loans in 2009. Most of the new credit was released by China's Big-Four stateowned banks and three policy banks. ${ }^{14}$ The stimulus package causes a sudden dramatic increase in newly issued bank loans in 2009, which is visualized in Figure 1.

Panel A plots the annual new bank loans scaled by GDP of that year together with the time series of GDP growth, over the period of 2004-2016. Whereas in normal years new bank loans are about $15 \%$ of the GDP in China, this number clearly stands out in $2009(27.5 \%)$ and $2010(19.2 \%)$. To address the concern that the unusually high ratio of new bank loans to GDP in 2009 might be driven by lower GDP of that year, Panel B in Figure 1 plots new bank loans each year scaled by 2004 GDP in 2004 fixed price (left scale), together with GDP levels for later years but in 2004 fixed price (right scale). The pattern is even more striking: new bank loans in the two years after 2008, especially 2009, stood out as abnormally high. Finally, Panels C and D show that most of the increase of new bank loans in 2009 are toward the non-residential sector (instead of the residential sector, which would be the case after the housing-related credit boom in 2016), consistent with the stimulus package being predominantly infrastructure-investment oriented. ${ }^{15}$

Although this paper focuses on the financing of local governments during and after the 2009 stimulus plan, note that not all additional new bank loans in that year went to local governments. The easy monetary policy, which Beijing pushed to help local governments obtain bank financing to implement the fiscal expansion, also led to abnormal bank credit growth to other sectors in China (see, e.g., in Cong et al. (2018)). ${ }^{16}$ Figure 2 provides the breakdown of 2009 abnormal new bank loans to various sectors as a result of the stimulus package. We estimate that a total of RMB 4.7 trillion extra in new bank loans was extended to the Chinese economy in 2009. LGFVs obtained roughly RMB 2.3 trillion of extra new bank loans in 2009, among which 2.06 (0.26) trillion came from commercial (policy) banks. The non-residential sector (excluding LGFVs) received about 1 trillion in extra new bank loans, and the remaining 1.4 trillion went to the residential sector (mainly in the form of mortgage loans). Appendix A provides details on how the sector-level abnormal bank loans in 2009 are estimated.

\footnotetext{
${ }^{14}$ The Big-Four stated-owned commercial banks are Industrial and Commercial Bank of China, Bank of China, Construction Bank of China, and Agricultural Bank of China; the three policy banks are Agricultural Development Bank of China, China Development Bank, and the Export-Import Bank of China. These banks, especially the latter three policy ones, are in general expected to support the country's economic and political agenda besides the usual goal of profit-maximization.

${ }^{15}$ Heavy infrastructure investment in 2009, which could be considered as part of the long-standing urbanization plan in China, is consistent with the rising land prices around 2009-2010 (Deng et al. (2015)), even without heated residential lending (to the household sector).

${ }^{16}$ As Premier Jiabao Wen stated in the 2009 Davos World Economic Forum, the success of the 2009 stimulus was due to the combination of "the proactive fiscal policy and moderately easy monetary policy."
} 


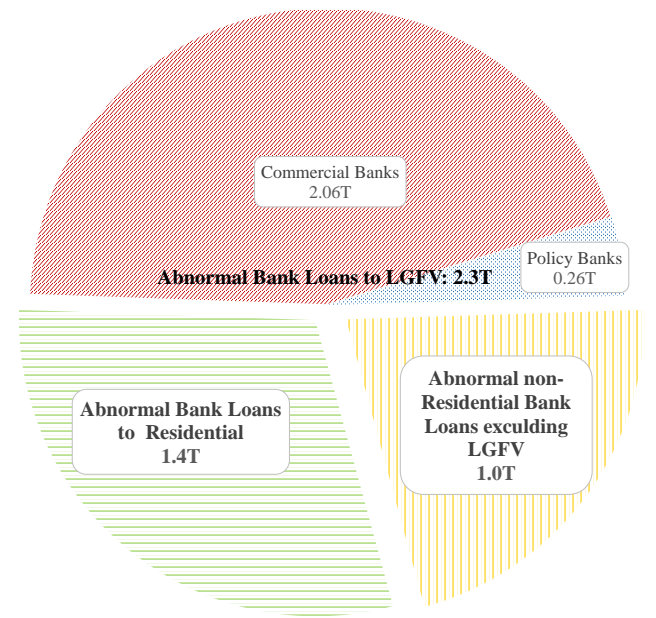

Figure 2: Decomposition of abnormal 2009 new bank loans extended to various sectors in the Chinese economy, with a total of RMB 4.7 trillion.

Several years later, the consequences of mounting debt obligations, to which we turn next, surfaced.

\subsection{Categories of Local Government Debt}

Shortly after the successful implementation of the stimulus package via LGFVs in mid 2010, many economists and practitioners raised warnings about the solvency of local governments, because it may jeopardize the steady growth of Chinese economy. What is worse, at that time, the central government had no direct statistics to even gauge the aggregate debt balance of local governments, let alone monitor the potential default risk of the LGFVs. This situation pushed the NAO to conduct the first nationwide survey on local government debt on December 2010. The same office published another somewhat more detailed official report, dated June 2013. These two NAO reports are the most authoritative documents that shape all discussions on this topic, and they provide detailed breakdown of China's local government debt in these two snapshots. We reproduce this information in Table 1.

\subsubsection{Categories of debt obligations}

We investigate the composition shift of four debt obligations reflected in the 2013 report: Bank loans, Municipal corporate bonds (MCBs), Munibonds, and Trust. ${ }^{17}$ As we explain

\footnotetext{
${ }^{17}$ Several liability items are significant but excluded from our later analysis. "Accounts receivable" is excluded due to its nature of working capital (not debt). "Built-to-transfer" is the usual source of financing in the Public-Private-Partnership (PPP); it is in the same nature as "Borrowing from entities E individuals," which involves private entities and local government. We, unfortunately, have no data
} 
later in this section, all of them are in the form of debt with implicit bail-out expectations from government, either local or central, and all of them are under the "shadow" of the traditional banking business in one way or another.

MCBs are public bonds issued by LGFVs (including corporate bonds, mid-term notes, and short-term bills in the mid-2013 report; see Table 1) that have implicit government guarantee (Liu et al. (2017)). We will turn to MCB in more detail in Section 3.1. A conservative estimate in Section 4.5 shows that in 2016, about $62 \%$ of MCBs were invested by WMPs, which are sold through commercial banks and considered the most important form of shadow banking in China (e.g., Acharya et al. (2017); Hachem and Song (2017a)).

Munibonds stand for municipal bonds issued by local governments. As explained, the 1994 Budget Law prohibited local governments in China from borrowing by themselves directly, but they may issue munibonds via the Ministry of Finance. In October 2014, the Ministry of Finance released its authority fully back to several municipalities, which were then allowed to issue and repay munibonds by themselves. As we argue shortly, this reform is likely a response to the stimulus-hangover effect, and starting in 2015, we observe a rapid growth of munibonds under the so-called local government bond-swap program (i.e., issuing munibonds to repay existing due debt) overseen by the Ministry of Finance. We will discuss this bond-swap program in the Conclusion.

Finally, Trust debt includes both trust loans (individuals to firms) and entrusted loans (firms to firms); both help channel funds to the non-financial sector outside the traditional commercial banking sector. Section 4.5 explains that traditional commercial banks play an important intermediating role in channeling both forms of loans, and hence they are widely considered the barometer of shadow banking activities in China. Starting from 2010, given the surging financing demand of LGFVs backed by local governments, one particular form of trust loans, termed trust-municipality cooperation, became popular.

\subsubsection{Contingency of debt obligations}

The NAO reports contain another dimension of the breakdown of local government debt: "fully guaranteed," "contingent obligation," or "contingent bailout obligation." The mere existence of these categories reflects the uncertainty toward the nature of debts assumed by LGFVs. Are they municipality debt? Or just corporate debt? In China, the rules and regulations are in flux, and the extent to which local governments are liable for the debt

source on this item. Finally, "Fiscal on-lending" captures borrowing from higher authorities (such as the Ministry of Finance). 
assumed by LGFVs is unclear. Given that LGFVs are enticed to implement the stimulus plan pushed forward by Beijing, which is the ultimate rule maker, investors naturally expect some forms of bail-out from local or central governments in case LGFVs default.

In response to this widespread perception, the State Council of China issued the 43th Document, "Opinions of the State Council on Strengthening the Administration of Local Government Debts," in September 2014. The "No. 43 Document" and the following regulatory rules banned local governments from providing guarantee to LGFVs' bond offerings, prohibited local governments from raising debt via LGFVs, and ordered local governments to restructure and substitute existing debt with munibonds. However, how strictly these rules are implemented is unclear. As explained in Section 5, some other new orders were coming out from other regulatory bodies to counter this strict ruling, and the government's implicit bailing-out on MCB and related debt was still widely expected among Chinese investors. As a result, although the net MCB issuance dropped to 1.1 trillion RMB in 2015 from the peak of 1.7 trillion in 2014, the number jumped back to around 1.5 trillion in 2016 .

\section{Bank Loan Wanes and Shadow Banking Waxes}

After describing our data sources, this section shows the time-series pattern that the debt liability of local governments in China has slowly shifted from mostly bank loans in 2009 to a significant fraction of non-bank debt after 2012. We then present evidence from various dimensions that is consistent with the stimulus-loan-hangover effect.

\subsection{Data Sources}

Our data come from various sources. Details of variable constructions can be found in Appendix B.

\subsubsection{Municipal corporate bond data}

LGFVs issue MCBs in five forms including exchange-traded corporate bond, enterprise bond, medium-term note, short-term financing bill, and private placement note. Throughout the paper, we use the term "corporate bonds" to refer to all of the above bonds, which are publicly traded in either exchanges or the interbank market. For each MCB issuance, WIND provides the bond-specific information, including actual issuing amount, issuing date, maturity date, issuer's province, bond rating, issuer's rating, and the purpose of raised funds. 
Mainland China has 31 provincial-level administrative divisions that have MCBs issued by LGFVs. We drop Xizang because it only has one MCB ever issued in our sample, leading to 30 provinces in our final sample. Following common practice, we also classify these 30 provinces of mainland China into seven geographic regions: North China, East China, South China, Center China, Northeast, Northwest, and Southwest.

For all MCBs except the private placement notes, the bond issuance prospectus provides information on the purpose of issuance proceeds. We manually read the prospectus and classify the issuance purpose into three categories: repayment of existing bank loan, investment in projects such as rebuilding shanty areas or constructing infrastructure, and others (including replenishing working capital, financing for other entities through entrusted loan structure, and undisclosed purpose). ${ }^{18}$

\subsubsection{Bank loans and other data}

Country and province bank loan data are from the People's Bank of China (PBoC), whereas trust and entrusted loan data are from the Aggregate Financing to the Real Economy released by the PBoC since 2011. The National Bureau of Statistics provides data on GDP (both country and province levels), provincial fiscal deficit measured as the fiscal expense minus the fiscal revenue, fixed-asset investment, and local government's land sale RMB value.

The structure of local government debt is estimated from 2008 to 2016, with details provided in Appendix B. Recall that the NAO provides two official auditing reports on local government debt that we recreate in Table 1. Annual Municipality-Trust cooperation data are reported officially by the China Trustee Association and are available on WIND. Data on bank loan balance of LGFVs before 2012 are from various validated news sources and are collected by WIND. Individual munibonds and MCBs are from WIND.

The aggregate WMP balance and the year-end balance of credit bonds by ratings are from WIND. We get the WMPs' holding in credit bonds by ratings from China Commercial Bank Wealth Management Products Annual Reports issued by the China Banking Wealth Management Registration System.

\subsubsection{Summary statistics}

Table 2 reports the summary statistics of the raw (Panel A) and abnormal (Panel B) values of various variables at the provincial level, where abnormal is defined as the excess

\footnotetext{
${ }^{18}$ We thank Yunjun Yu and Yilin Zhang for providing more recent MCB purpose data, which improves our original data by finer classifications.
} 
value over the 2004-2008 average. Each year, on average, a province issued MCBs worth $2.2 \%$ of its GDP over the period of 2012-2015. The number is quite similar $(2.1 \%)$ if we subtract the average of the 2004-2008 MCB/GDP, suggesting LGFVs issued few MCBs in early years. The cross-provincial average 2009 bank loan (BL)/GDP is $27.5 \%$ with an abnormal BL/GDP of $16.4 \%$, which is an increase of around 1.5 times from the 20042008 average of $11.1 \%$. By contrast, we do not see much of an increase in the 2008Q1-Q3 BL/GDP.

\subsection{Evolution of Debt Obligations of Local Governments}

\subsubsection{Credit policy tightening and rollover pressure}

Witnessing the wild surge of bank credit in 2009, Beijing realized that the policy-driven credit boom may grow out of control, with potential distortions and liquidity overhang being devastating to the economy. As early as January 10, 2010, a Financial Times article titled "Beijing Seeks to Curtail Bank Lending 'Binge' " reported that banks were expecting the government to tighten the monetary policy in the following months. ${ }^{19}$ In Figure 1, we observe that the ratio of new bank loans to GDP, following the unprecedented, high level of $27.2 \%$ in 2009 , dropped to $19.2 \%$ in 2010 (which still exceeded the normal level); the credit policy reverted to its normal level afterwards. The somewhat unexpected credit tightening following 2009 pushed local governments to explore other sources of financing for their on-going investments. Our paper highlights another more distinct channel. These stimulus loans were backed by infrastructure projects whose cash inflows likely occur in the remote future. Kroeber (2016) explains this classic "maturity mis-match" of Chinese local governments by writing "Localities often used three- to fiveyear bank loans to finance infrastructure projects whose economic benefits (and revenue streams, if any) would only materialize over two or three decades." More precisely, Gao et al. (2018) report in their Table 1 that the average loan maturity is 4.1 years for all loans borrowed by large LGFVs with an annual credit line of at least RMB 50 million from the largest 19 banks. Naturally, LGFVs faced unprecedented heavy pressure to roll over the loans coming due about three to five years later. ${ }^{20}$

\footnotetext{
${ }^{19}$ The report writes "the authorities $(C B R C)$ had ordered some Chinese banks temporarily to halt lending altogether after the sector extended a total of 1.1 trillion $R M B$ in new loans in just the first two weeks of January." URL: http://www.ft.com/cms/s/0/320cf850-0a1a-11df-8b2300144feabdc0.html?ft_site=falcon\&desktop=true\#axzz4SeC0xGT8.

${ }^{20}$ Chen and $\mathrm{Gu}(2012)$ analyze in length the situation of local government debt after the 2009 stimulus plan, together with its potential impact on the commercial banking system in China. In that paper, according to an internal report by CBRC, standing at November 2010, the bank-loan-due schedules for LGFVs are RMB 0.8 trillion due in one year, 2.2 trillion due after one year but before three years, 3.5
} 


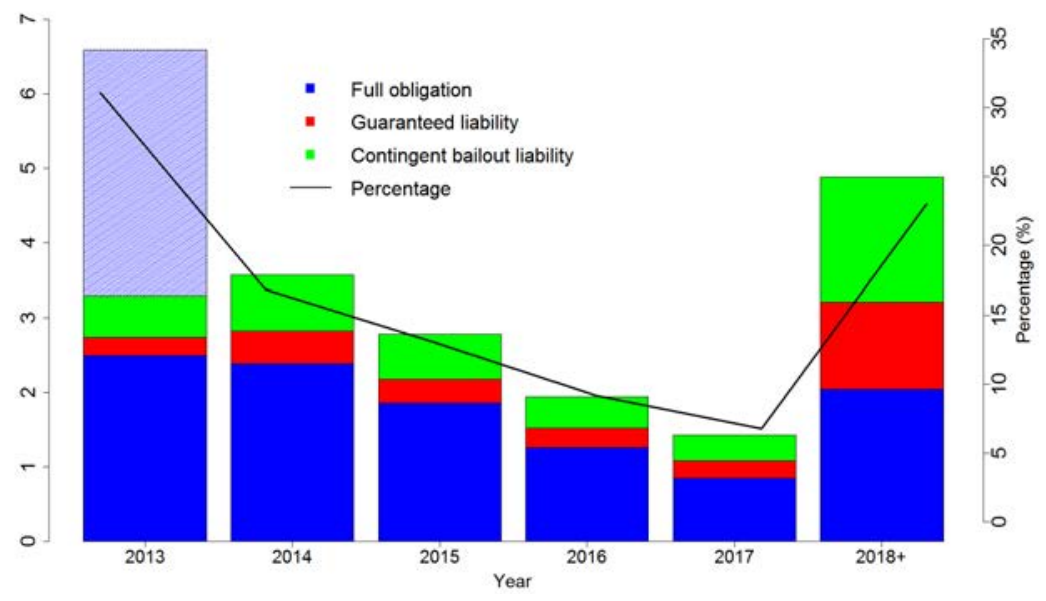

Figure 3: Local Government Debt-Due Schedule as of June 30, 2013. The total outstanding local government debts are classified into three categories: full obligation, guaranteed liability, and contingent bailout liability. We assume the debt due at the first half of 2013 is the same as the debt due at the second half of 2013. Data source: local government debt auditing report in 2013 issued by the NAO.

Figure 3 gives the detailed debt-due schedules standing on June 30, 2013. Because June 2013 is the mid of that year, we simply double the debt due in the second half of 2013 to proxy for the debt due that year (indicated by the hatched area). The magnitude of rollover pressure starting from 2013 was enormous. Local governments needed to pay back about RMB 3.25 trillion of debt in the second half of 2013 (so about RMB 6.5 trillion in the whole year of 2013), and about RMB 3.5 trillion in 2014. To put these numbers into perspective, they account for about $45 \%$ of local government debt obligations, and most of these soon-to-be-due debt obligations are bank loans. This mounting rollover pressure is why at that time, leading economists in many institutions were concerned about the debt situation of China's local government debt.

\subsubsection{Bank loans down, non-bank debt up}

Facing tightening/normal credit policy, local governments responded by resorting to the non-bank debt mentioned above, either to refinance part of maturing bank loans or finance their continuation investments. For LGFVs with the full flexibility to choose whom to borrow and/or refinance from, the easiness and the rate at which they can obtain financing is what matters. The trade-off has slowly leaned toward non-bank sources since 2012; for instance, from loan pricing terms, tapping credit from MCBs trillion after three years but before 10 years, and 2.6 trillion after 10 years (see their Figure 12). 
rather than bank loans has become more attractive. ${ }^{21}$

As the main result of this section, Figure 4 depicts the evolution of total local government debt balance and the composition of each category (Panel A) and the evolution of the percentage for each category (Panel B). We indicate the NAO (i.e., National Audit Office) on December 2010 and June 2013 to highlight that these two snapshots are authoritative numbers from national auditing reports. We have tried our best (as explained below) to fill in the entire time series for each category from 2008 to 2016; for details, see Appendix B. The data of total local government debt are from the two NAO auditing reports $(2008,2009,2010,2012)$, interpolation $(2011,2013)$, and public news releases $(2014,2015,2016)$ from regulators. WIND provides the accurate issuance data for munibonds and MCBs. The evolution of Trust loans is estimated by combining the snapshot of the total Trust loans to local government in the mid-2013 NAO auditing report, together with the annual outstanding balances of Municipality-Trust cooperation; see Appendix B.5 for details.

For bank debt, the president of CBRC (Fulin Shang) regularly reveals the aggregate exposure of the banking system to local governments via the official website of CBRC (and WIND recorded this information over time) before June 2013. Afterwards, this information seems to have started to become sensitive and hence is no longer available on the CBRC website. Instead, we resort to the annual reports of listed commercial banks, hoping some banks keep reporting their loan exposures to local governments. Only one of the Big-Four banks (Construction Bank of China) reported this information, based on which we construct the outstanding bank loans to local governments of the entire banking sector after June 2013. We acknowledge it is much less accurate than the numbers before June 2013, and hence indicate them with dashed line in both panels of Figure 4.

Figure 4 serves two purposes. The first is more for fact-recording, because we have produced perhaps the most reliable estimates (based on public information only) for local government debt and its various compositions. The second is our main point: starting in 2012, besides the fast growth of the total debt balance of Chinese local governments (from RMB 5.6 trillion in 2008, 17.4\% of GDP, to RMB 26.8 trillion in 2016, 36.0\% of GDP), we also see a steady and noticeable composition shift from bank loans to nonbank debt. In fact, this point is already quite evident based on the two NAO reports only. Bank loans were about $80 \%$ of total local government debt at the end of 2010, which dropped to below $60 \%$ in the mid-2013 report. By contrast, the fraction of bonds

\footnotetext{
${ }^{21}$ According to practitioners, the loan rate that LGFVs can obtain from banks is about $110 \% \sim 115 \%$ of the benchmark lending rate set by the PBoC. In 2012, based on the information of the prevailing benchmark lending rate and MCB rate, we find the LGFV bank borrowing rate exceeds the MCB rate by about 2 percentage points.
} 


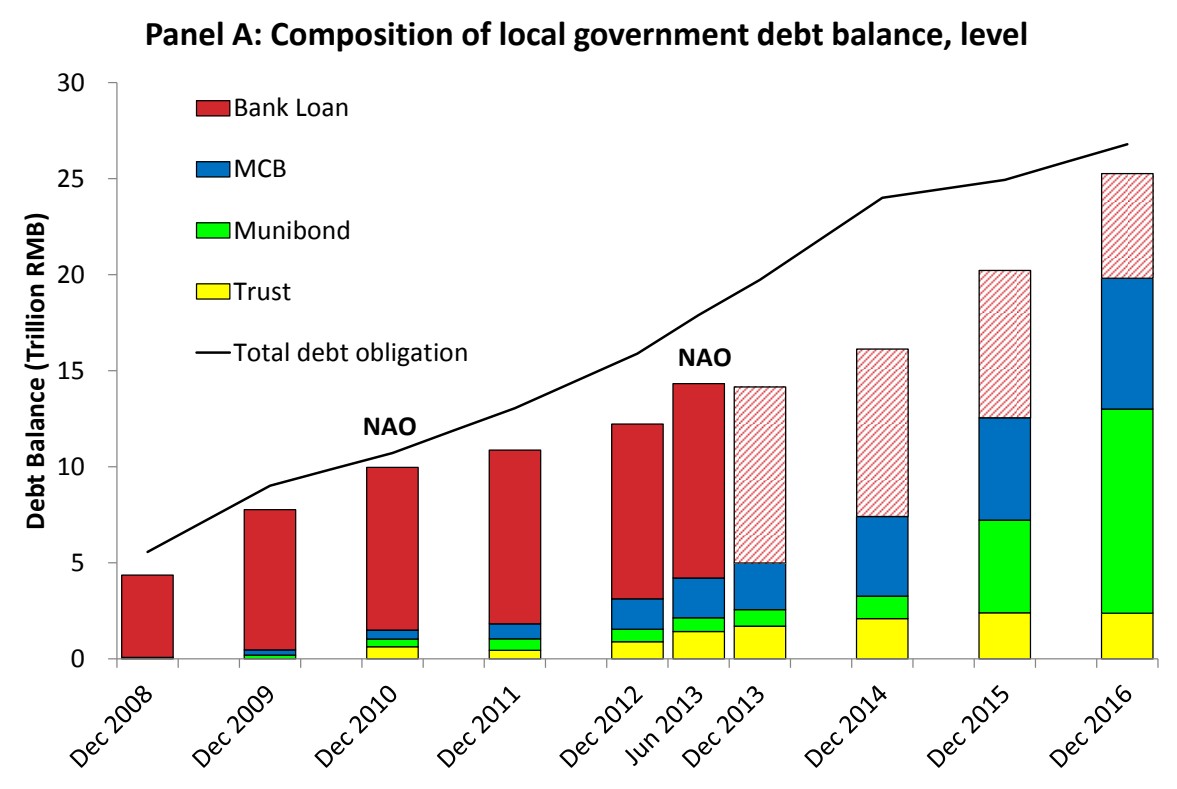

Panel B: Composition of local government debt balance, \%

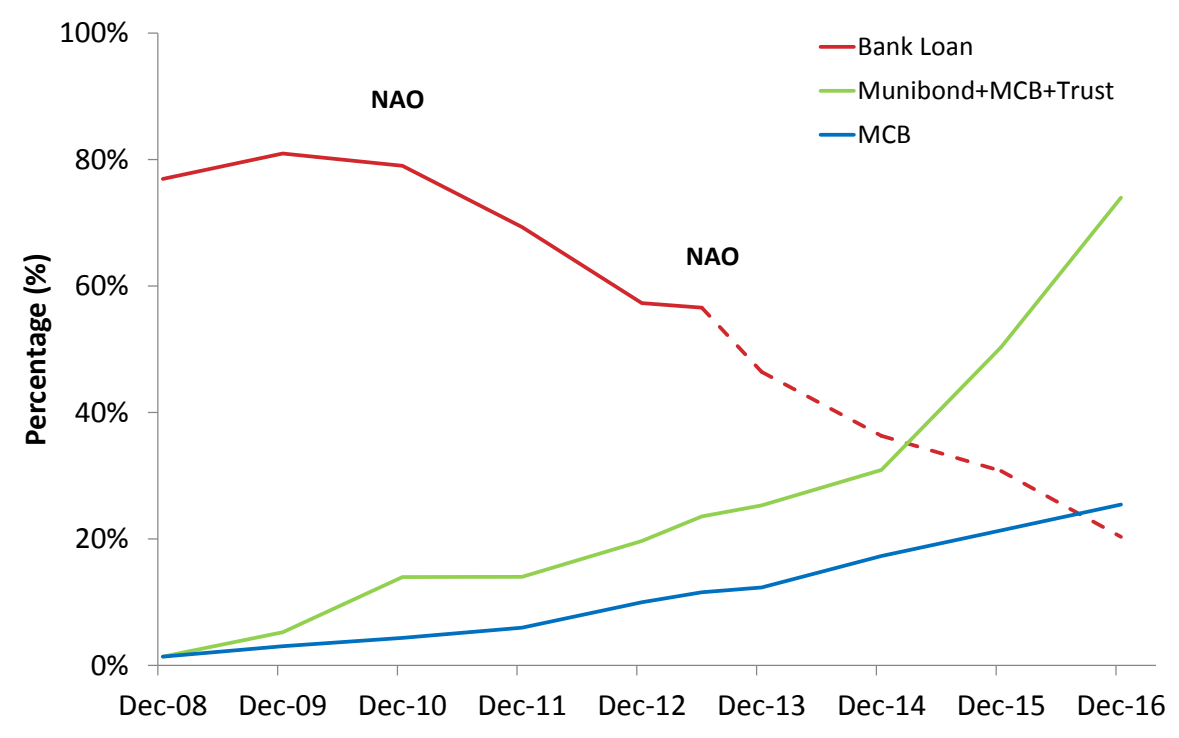

Figure 4: Local Government Debt Composition, 2008-2016. Panel A plots the composition of local government debt balance in trillion RMB, and Panel B plots the percentage of local government debt balance by composition. Four forms of local government liability include bank loan, municipal corporate bond, municipal bond, and trust. The data-construction details are in Appendix A. 
rose from $7 \%$ in 2010 to $10 \%$ by mid-2013 (and grew dramatically afterwards).

\subsection{Direct Evidence from MCB Prospectuses}

We now present the first evidence on MCB that supports the stimulus-loan-hangover effect. Figure 5 Panel A plots the evolution of the MCB-issuance activities over the period of 2004 to 2016, with new bank loans over GDP in the background. The solid line depicts how the total gross MCB issuance evolves over time. We start observing a steady growth of MCB issuance only starting 2009, with two notable jumps in 2012 and 2014. The dashed line plots the net MCB issuance (gross issuance minus those matured in that year). The difference between solid and dashed lines is negligible before 2015, indicating the rollover pressure from maturing MCB is not much of a concern until 2015. As explained in the data section 3.1.1, because most MCBs (except private placement note) is a public offering, every LGFV that is issuing MCB has to provide a prospectus, in which the bond issuer reveals the purpose of issuance. We group various issuance purposes into three categories: investment, repaying bank loans, or others (e.g., replenishing working capital, financing for other entities, undisclosed purpose, etc.); for details, see Section 3.1.1. Panel B in Figure 5 plots the time series of each category over the period from 2008 to 2016. We observe that in the first two years right after stimulus (2009 and 2010), almost all MCB issuance was for investment, which is likely to be a continuation of those long-term infrastructure projects started in 2009. But repaymentdriven MCB issuance has picked up its pace since 2011; it reached about a quarter of total MCB issuance in 2013, and experienced a blasting growth afterwards. In 2015, more than half of MCB-issuance deals are for repaying maturing bank loans.

Although a noticeable magnitude difference appears to exist between bank loan over GDP (left scale) and MCB issuance over GDP (right scale) in Figure 5, note that quantitatively our story matches with the data fairly well. Recall Section 2.1.2 explains that of the total RMB 4.7 trillion abnormal bank loans, RMB 2.3 trillion went to LGFVs. Since the 2009 stimulus loans occurred one time only, our mechanism implies that the cumulative issuance of non-bank debt instruments (e.g., MCB and Trust) for debt repayment during 2012-2015 should roughly match with this RMB 2.3 trillion number. In the data, the cumulative issuance amount is RMB 2.1 trillion by the end of 2015, with 1.4 trillion from $M C B_{\text {repay }}$ and 0.7 trillion from trust financing. ${ }^{22}$

\footnotetext{
${ }^{22}$ The cumulative LGFV trust debt increase is RMB 1.9 trillion from 2012 to 2015 . We do not have information to obtain the loan-repayment part of the LGFV trust issuance. However, the China Trust Association provides the number on the fraction of the quarterly loan-type trust balance. We use this number to estimate the cumulative trust issuance for loan repayment to be RMB 0.7 trillion.
} 

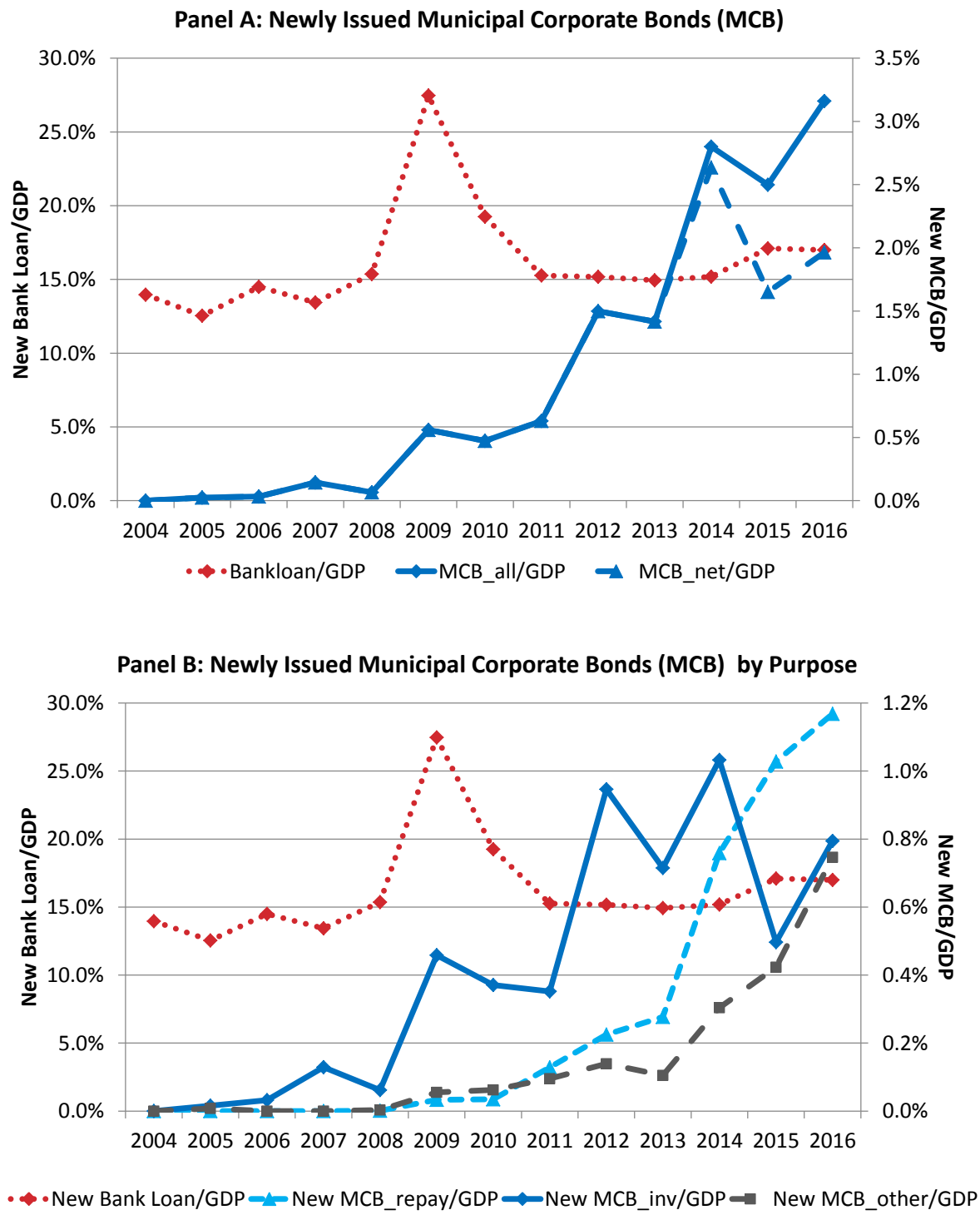

Figure 5: Municipal Corporate Bond Issuance, 2004-2016. Panel A plots the total MCB issuance over GDP, the net MCB issuance over GDP, and new bank loans over GDP. Panel B plots the total MCB issuance over GDP by usage, including repayment of bank loans, financing of an investment, and other purposes. The new bank loans over GDP are plotted against the left vertical axis and MCB issuance over GDP is plotted against the right vertical axis. The annual MCB-issuance data are aggregated from individual municipal corporate bonds downloaded from WIND. 


\section{Cross-Sectional Evidence and Links to Shadow Bank- ing}

Taking the stock of time-series evidence so far, we have painted the following picture: in 2009, China's local governments took on massive stimulus bank loans, and about three to five years later they resorted to non-banking financing to either continue their ongoing long-term investment or roll over their maturing bank loans. Based on the municipal-level MCB data, this section explores the cross-sectional implication of the stimulus-loan-hangover mechanism, which predicts that the more bank loans an area was taking on in 2009, the more MCBs in that area would be issued in the years after 2012. In Section 4.5, we connect the shift toward non-bank debt with shadow banking activities in China, which has experienced "barbarian growth" since 2012.

Note one additional advantage offered by MCB that is important for our empirical test. In general, for cross-sectional analysis, researchers need to be careful in distinguishing between the source of funds and the use of funds, especially when studying shadow banking. Wealthy individuals in developed coastal cities (e.g., Shanghai) often buy WMPs that are backed by trust products investing in some projects from underdeveloped inner land cities (e.g., Qinghai). Consider the alternative of collecting data on individual trust products that are also available on WIND. Although the prospectus of a typical trust product also identifies perfectly where the funds get raised, only extremely vague information - often nothing at all - is available on where the funds are used. By contrast, because MCBs are issued for the infrastructure projects in particular regions, we know the use of funds, i.e., where the funds go to. This is clearly what our cross-sectional prediction is about.

\subsection{Main Hypothesis}

The stimulus-loan-hangover mechanism discussed above has the following hypothesis with a straightforward cross-sectional prediction.

Hypothesis. If a region/province was more aggressive in taking on bank loans in 2009, this region/province will issue more MCBs several years later.

To test this hypothesis, for each province/region, we first construct the "abnormal" bank loan over GDP at 2009, which is defined as the 2009 value minus its average in the past five years (here, BL stands for bank loans and " $\mathrm{i}$ " indicates province/region):

$(2009 \text { Abnormal BL/GDP })_{i}=(2009 \mathrm{BL} / \mathrm{GDP})_{i}-(\text { Average BL/GDP 2004 08 })_{i}$. 
Similarly, we construct the provincial/regional "abnormal" MCB over GDP in each future year from 2012 to 2015 :

$$
(201 \mathrm{t} \text { Abnormal MCB } / \mathrm{GDP})_{i}=(201 \mathrm{t} \mathrm{MCB} / \mathrm{GDP})_{i}-(\text { Average MCB/GDP 2004 08 })_{i} \text {, }
$$

for $t=2,3,4,5$. Our regressions treat (2009 Abnormal BL/GDP) as the independent variable, whereas (201t Abnormal MCB/GDP) as the dependent variable, i.e.,

$$
(201 \mathrm{t} \text { Abnormal MCB/GDP })_{\mathrm{i}, \mathrm{t}}=\alpha_{t}+\beta_{t}(2009 \text { Abnormal BL/GDP })_{\mathrm{i}}+\operatorname{Controls}_{i, t}+\epsilon_{i, t} \text {. }
$$

Later, we also run a panel regression in which we pool together observations from different years (2012-2015) (so that $\alpha_{t}$ and $\beta_{t}$ no longer depend on $t$ ), and report standard errors robust to two-way clustering at the province-year level.

To address the potential concern of a significant cross-region disparity in financial development in China, we have taken out the past-five-years average of BL/GDP for each province when constructing the key independent variable (i.e., 2009 Abnormal BL/GDP) in (1). In other words, 2009 Abnormal BL/GDP captures the heterogeneous deviations - here, the aggressiveness in credit expansion - in response to the stimulus plan away from the province-dependent steady state. This treatment is particularly attractive in light of Panel B in Figure 1, which shows a steady pattern between new bank loans and GDP in China.

We emphasize that it matters little whether the variation in 2009 Abnormal BL/GDP was driven by demand-side shocks (e.g., LGFVs in some provinces were aggressive in launching infrastructure projects in 2009) or supply-side shocks (e.g., banks in some provinces were pushed by Beijing to lower their lending standards). Either way, the rollover channel says that bank loans taken in 2009 need to be repaid when these bank loans become due, giving rise to heterogeneous rollover pressures in later years across provinces.

What raises concerns of $\beta_{t}$ in (2) to be biased is that, at the province level, 201t Abnormal MCB/GDP in later years - which may be neither for loan repayment nor for continuing phases of 2009 infrastructure projects - is correlated with 2009 Abnormal BL/GDP given regional disparity in China. We have two approaches to address this problem. First, in regression (2), we include province-level economic variables, for example, province GDP growth, that the prior literature has found to be relevant for MCB issuances. These results are reported in Section 4.2. Second, in Section 4.3, we introduce an instrumental variable that exploits the timing of the terms of local governors; this 
variable captures heterogeneous demand-side shocks to 2009 abnormal bank loans but are arguably orthogonal to the future MCB/GDP growth across provinces.

\subsection{Cross-Sectional Evidence: MCB Issuance}

Panel A in Figure 6 gives the regional scatter plot between the 2009 abnormal bank loan and MCB issuance for each year from 2012 to 2015. The "Southwest" region, where the Wenchuan earthquake in May 2008 occurred, had the largest abnormal bank loan growth in 2009 for post-disaster reconstruction. Consistent with our hypothesis, this region ranked top in its abnormal MCB issuance in three out of four later years. Panel $\mathrm{B}$ then zooms in further to present the provincial scatter plot.

Table 3 conducts the formal regression analysis for each year. Panel B says that crosssectionally, the 2009 abnormal bank loan growth positively predicts the abnormal MCB issuance in that province, with a 1\% level of significance in both 2013 and 2014, and magnitude-wise, we obtain similar coefficients over years. The statistical insignificance in 2012 but significance in later years is reasonable; according to Figure 5, the stimulus-loanhangover intensified after 2012. For 2015, munibonds issuance due to the new Budget Law passed in late 2014 relieved part of the rollover pressure of local governments.

Panel C of Table 3 presents the results of provincial regressions with economic controls. We follow Bai et al. (2016) to include abnormal fiscal deficit over GDP, abnormal fixed-asset investment over GDP, abnormal land sale over fiscal revenue, and GDP growth, all in the same year and the same province as the abnormal MCB issuance. ${ }^{23}$ We also include the "corruption index" developed by Ang et al. (2017) as a control. This index is a political-rank-weighted number of corrupted officials, capturing the severity of provincial political risk. The 2009 abnormal bank loan growth positively predicts the abnormal MCB issuance in years 2013 to 2015. The coefficient in front of the province GDP growth is always significantly positive across different specifications, reflecting the mechanical relation between economic activities (GDP) and investment (financed by MCB). The corruption index has a positive coefficient and is marginally significant (significant at the $5 \%$ level for 2013), suggesting provinces with loose governance were issuing more MCB during 2012-2015.

\footnotetext{
${ }^{23}$ Throughout the paper, "abnormal" means we take the year $t$ observation and subtract its average between 2004 and 2008 except where specified.
} 

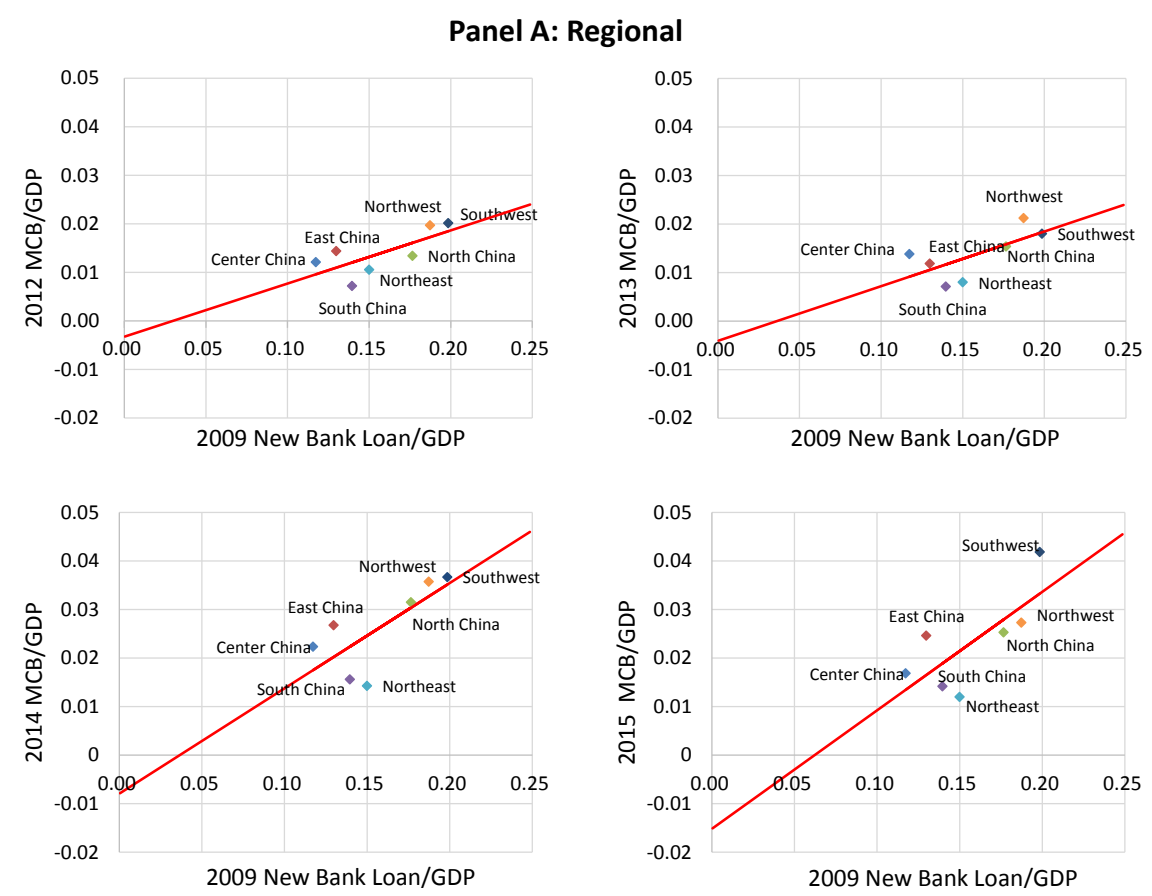

Panel B: Provincial
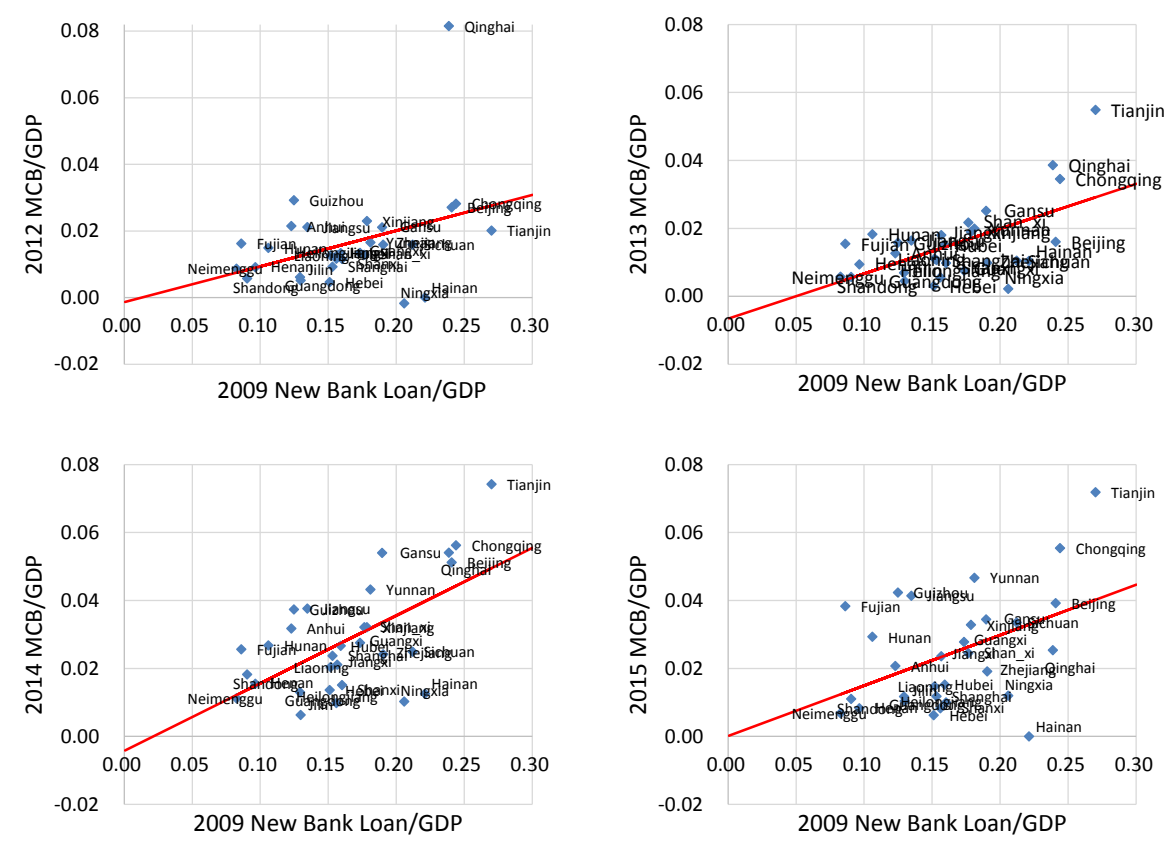

Figure 6: 2009 Abnormal New Bank Loan and 2012-2015 Abnormal Municipal Corporate Bond Issuance. Panel A (B) presents the scatter plot with a fitted line for regional (provincial) data. Abnormal new bank loan and abnormal MCB issuance (as a percentage of GDP) are calculated over their average values between 2004 and 2008, respectively. The bank loan data are from the People's Bank of China, and the MCB-issuance data are from WIND. 


\subsection{The IV Approach}

Whereas from the accounting perspective, local governments have to repay matured stimulus loans, as economists, we are still interested in whether the variation in the 2009 abnormal bank loan was driven by demand-side or supply-side shocks. In addition, a carefully designed IV helps us guard against the concern that the results in Section 4.2 are merely correlation rather than causality.

\subsubsection{The IV: Is the governor in his/her early term?}

We first construct the provincial-level dummy variable EarlyTerm E $_{i, 09}$, which takes a value of 1 if the governor of a province $i$ was in his/her first two years of the official term as of 2009, and 0 otherwise.

The IV EarlyTerm En $_{i 09}$ aims to capture the demand-side shock to stimulus bank loans in 2009. ${ }^{24}$ In China, an official term of a provincial governor is typycal five years. After this term, he or she can get promoted, stay in the same official rank, or retire. The incentive to comply with Beijing will be stronger in later years in a governor's term, and newly appointed governors may need time to become familiar with their provinces before they launch new investment projects.

As a result, when the stimulus policy shock hit in 2009, we expect more aggresive bank lending in provinces with governors in their third year or later, because those governors were more motivated to follow Beijing's order. On the other hand, provinces with new governors were relatively less sensitive to the 2009 stimulus plan as these governors were less likely to get promoted anyway. Therefore, the 2009 cross-province variation in governor's official term, EarlyTerm E $_{i, 09}$, serves as a candidate IV for the 2009 stimulus loan. ${ }^{25}$

\footnotetext{
${ }^{24}$ We have also tried another instrument based on the supply-side story. Borrowing the idea from Acharya et al. (2017), for each province, we construct $B O C$ expo $_{i}$ as the average branch fraction of Bank of China (BOC) over 2004 to 2008, because the president of BOC in 2009 was Gang Xiao, who strongly supported the central government relative to his peers by aggressively lowering lending standards and extending stimulus loans in 2009. However, this instrument turns out to be quite weak (insignificant in the first stage).

${ }^{25}$ This IV has been used in the literature. Li and Zhou (2005) show that the most important determinant in the promotion decision is the local economic growth relative to other provinces. Tan and Zhou (2015) find that both bank loans and fixed-asset investments at the provincial level peak in the third and fourth year of a provincial governor's term. On the other hand, Ru (2018) finds that city-level China Development Bank loans increase most in the first two years of a city official's term. This finding implies an opposite relationship between bank loans and government officials' first-two-year term at the provincial and city levels. Our personal discussion with Ru attributes this discrepancy to a much faster turnover for city-level officials and hence stronger incentives to boost local economic growth right after the appointment.
} 
Finally, the exclusive restriction requires that other than the rollover channel, EarlyTerm E $_{i, 09}$ is uncorrelated with other disturbances to 201t Abnormal MCB/GDP for $t$ ranges from 2012 to 2015. The rollover channel is likely there. Beijing reverted back to the normal monetary policy after 2010 and imposed strict restrictions on new LGFV loans in the following years. Those governors who were in their first two-year term as of 2009 would be in their late term years, and hence would have a strong incentive to comply with Beijing (by turning to other refinancing sources such as MCBs) for promotion.

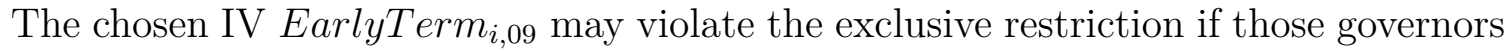
who turned from their early terms in 2009 to their late terms in 2012-2013 and therefore somehow became aggresive in seeking GDP growth then. We have three answers. First, though a valid concern, especially for the Chinese economy in its early growth phase (e.g., Li and Zhou (2005)), this force is greatly attenuated in our sample period after Xi Jinping took power in 2012 and vowed to address this problem. ${ }^{26}$ Recent research emphasizes the multi-dimensional performance measures for the political tournament among Chinese local governors (Jia et al. (2017)). Second, our strongest result is in 2014, when EarlyTerm $_{i, 14}$ has almost zero correlation (0.5\%) with EarlyTerm E $_{i, 09}$. Last but not the least, in our panel regressions, any periodic variation caused by the local governor's five-year term will be smoothed over the four-year period 2012-2015, greatly alleviating the concern of cross-province variations caused by our instrument EarlyTerm E $_{i, 09}$.

\subsubsection{Results of IV estimation}

Panel A of Table 4 presents the results of the first-stage IV estimation. Consistent with the demand-side interpretation, provinces with newly appointed governors had fewer stimulus loans in 2009. ${ }^{27}$ In the second stage, Panel B reports that the instrumented 2009 abnormal bank loan predicts future province-level MCB issuance in the cross section, year by year. The coefficients are similar in economic magnitude to those OLS estimates in Panel A of Table 3 with statistical significance at 5\%, indicating little endogeneity concerns for our main OLS results. The panel regression of the second-stage estimation is reported in Panel $\mathrm{C}$ of Table 4, with similar findings. Overall, the exogeneous variation captured by the demand-side IV confirms the causal relation between stimulus bank

\footnotetext{
${ }^{26}$ See a link in People's Daily (Beijing's mouthpiece; http://renshi.people.com.cn/n/2013/1210/c13961723793408.html), which delivers a notice from the Party's organization department that multiple factors other than economic growth would be taken into consideration for government officials' promotions. In addition, environmental protection is emphasized when assessing officials' performance (http://time.com/3848171/china-environment-promotions/).

${ }^{27}$ Due to the small-sample-size problem (only 30 provincial-level data points are in the first stage), the $F$-test value only clears the Stock-Yogo weak IV test at the $20 \%$ level. We acknowledge this potential issue in interpreting our IV results.
} 
loans in 2009 and MCB issuance in later years.

\subsection{Robustness and Further Evidence}

We provide further validating evidence for our stimulus-loan-hangover mechanism, and discuss the economic magnitude of our estimated coefficients.

\subsubsection{Placebo test of 2008 bank loan growth}

Table 5 presents the placebo test, which considers the 2008Q1-Q3 abnormal bank loans for each province as the explanatory variable; we focus on the first three quarters of 2008 because the stimulus plan started in November 2008. Similar to the construction of 2009 abnormal bank loans, 2008Q1-Q3 abnormal bank loans in each province are defined as the 2008 first-three-quarters new bank loans over the GDP of that period, minus their average over the past four years (2004-2007). The concern about seasonality is minimal because we are exploiting the cross-province variations in the bank loan growth in the first three quarters.

According to our mechanism, the cross-province pattern of 2008Q1-Q3 abnormal bank loans cannot explain the cross-province pattern of future MCB issuance in 20122015, and this test also helps rule out the standard concern that some pre-trend exists for the cross-province distribution of 2009 abnormal bank loans. Panel A in Table 5 first replaces the independent variable with the 2008Q1-Q3 abnormal bank loans. As expected, none of the coefficients in front of the new explanatory variable are significant for years 2012-2015. Panel B further combines both 2008Q1-Q3 and 2009 abnormal bank loans in the regression, and provides a formal statistical test for the hypothesis of equal coefficients in front of two abnormal bank loans. The $F$-statistics reported in Panel B reject this hypothesis at the $10 \%$ level for 2012 and 2013, the $1 \%$ level for 2014, and the $5 \%$ level for 2015 .

\subsubsection{Panel regression results}

Table 6 reports the panel regression results when we group togher the MCB-issuance observations for years 2012-15, with province-level controls that are relevant for the MCB issuance by local governments. The first column has no controls, whereas in the second column we include the same control variables as in Panel $\mathrm{C}$ of Table 3; both give a statistically significant coefficient in front of 2009 Abnormal BL/GDP. We include the

year fixed effect in the regression, and report $t$-statistics double-clustered at province and year levels (so errors can be correlated for the same province or the same year). 
Comparing our panel regression result in Table 6 with those separate regressions in Table 3, we note that the coefficient for 2009 Abnormal BL/GDP, which is about 0.15, is relatively stable across all specifications, either panel or year-by-year regression, with controls or without. This observation lends further support for the robustness of our result.

\subsubsection{MCB issuance by purposes}

Recall that we have information on why LGFVs are issuing MCB, because about $80 \%$ of MCB issuances publish prospectuses revealing their issuance purposes (except private placement notes; see Section 3.3). The MCB sample with prospectus information is representative of our entire MCB sample. ${ }^{28}$

We repeat the same cross-sectional analysis for three different kinds of usage: investment $\left(M C B_{\text {inv }}\right)$, bank loan repayment $\left(M C B_{\text {repay }}\right)$, and others $\left(M C B_{\text {others }}\right)$. We present the results in the next three columns in Table 6. In our framework, the stimulusloan-hangover effect is reflected in $M C B_{\text {repay }}$ and part of $M C B_{i n v}$, as the latter includes the MCB issuance for continuing investment started in 2009. However, we expect only $M C B_{\text {repay }}$ to be significant in our regression, a prediction confirmed in Column 3 in Table 6, because we have controlled local economic activities (e.g., local GDP growth), which should have absorbed the effect of continuing investment in that region.

\subsubsection{China Development Bank and the effect of loan maturity}

Provinces with longer maturity loans received in 2009 are likely to face less rollover pressure in later years. Unfortunately, we do not have provincial-level loan-maturity data. In the literature, Gao et al. (2018) use loan-level data from the largest 19 banks (including 18 commercial banks and China Development Bank, hereafter CDB) during 2007-2013H1 for LGFVs with an annual credit line over RMB 50 million. ${ }^{29}$ According

\footnotetext{
${ }^{28}$ The fraction of MCB with prospectus information, i.e., issuances excluding private placement notes, is $81.6 \%$ in RMB value and $79.7 \%$ in number of bonds, indicating no systemic size bias in the sample with prospectus information. And we should find little concern about whether LGFVs use private placement notes to avoid releasing the loan rollover information, because this type of information is required to be revealed to private investors anyway even in private placement notes.

${ }^{29}$ Note that our main explanatory variable, 2009 Abnormal BL/GDP, includes both abnormal LGFV loans and non-LGFV loans. We could have used the proprietary data from Gao et al. (2018) to construct 2009 Abnormal LGFVBL/GDP. We are grateful to Gao et al. (2018) to share part of the data to construct this variable, and indeed we obtain similar results reported in Appendix D. However, we decide not to use the LGFVBL/GDP variable for a few reasons. First, the LGFV dataset in Gao et al. (2018) only covers loan information of large LGFVs with an annual credit line greater than RMB 50 million. This approach may introduce bias for the coverage across provinces, because the distribution of LGFV size could be different for economically developed and under-developed provinces. Second, the dataset includes loan
} 
to their data, the average maturity of 2009 newly issued LGFV loans is 4.1 years for commercial banks and 7.2 years for CDB. The longer maturity of CDB loans is due to the different objective of CDB compared to profit-seeking commercial banks: as the largest one among the three policy banks in China, CDB is established to promote China's economic development and improve social welfare, and thus usually provides longer maturity loans to support local governments' long-term infrastructure investment.

This interesting observation implies provinces that received more longer-term CDB LGFV loans in 2009 should issue fewer MCBs during 2012-2015, conditional on the same amount of 2009 abnormal bank loans. To test this hypothesis, we include the interaction between 2009 Abnormal BL/GDP and the fraction of CDB-issued LGFV loans over total LGFV loans in 2009 in our benchmark regression. As shown in Table 7, the coefficients of this interaction term are negative and significant for all regressions except for 2012. This finding supports our story that the hangover effect of 2009 stimulus bank loan is less severe for local governments with longer-maturity CDB stimulus loans.

\subsubsection{Economic magnitude}

The last column in Table 6 provides the economic interpretation of our regression coefficient. In a crude sense, the coefficient in front of 2009 Abnormal BL/GDP in the regression of $M C B_{\text {repay }}$ reflects the annual bank loan repayment, which corresponds to the inverse of loan maturity. To facilitate this interpretation, we make two crucial adjustments to our regression. First, for each province, we scale future MCB issuance by its 2009 GDP, which is the same scaling as the explanatory variable (2009 Abnormal BL/GDP). Second, ideally, the regression coefficient should be identified from different bank loans taken by different provinces in 2009, rather than the cross-sectional divergences in provincial GDP levels. To mitigate the GDP-driven divergence of observed abnormal BL/GDP, we sort provinces based on their 2009 GDP and take the 10 provinces that have the most similar level of GDP in 2009. ${ }^{30}$

The resulting coefficient for 2009 abnormal bank loans, when explaining the MCB issuance for bank loan repayment, is 0.15. Taking into account that about half of the

information from the largest 19 banks, but LGFVs in some provinces may prefer borrowing from local small banks than do LGFVs in other provinces. Third, the LGFV dataset has a short coverage period from 2007 to 2013H1, which results in less accurate estimates of normal-period loan-to-GDP ratios.

${ }^{30}$ These 10 provinces are Yunnan, Chongqing, Jilin, Shanxi, Tianjin, Jiangxi, Guangxi, Shan_xi, Heilongjiang, and Neimenggu. To select the 10 provinces with the most similar level of GDP in 2009, we first rank all 30 provinces according to their 2009 GDP values. We then examine groups containing 10 sequentially sorted provinces, i.e., group one contains province 1 (highest GDP value) to province 10, group two contains province 2 to province 11, and so on. The selected group has the smallest "divergence" ratio, which is defined as the difference between the top and the bottom GDP divided by the mean GDP. 
abnormal bank loans go to LGFVs (see Figure 2), this coefficient implies that if an LGFV borrows an extra dollar in 2009, then after 2012, this LGFV needs to issue 30 cents more MCB each year to pay back bank loans. This estimate implies an average maturity of 3.5 years, which squares well with the average maturity of 4.1 years of 2009 loans issued by the largest 19 banks to large LGFVs documented in Gao et al. (2018), as well as the reported three- to five-year bank loan maturity by Kroeber (2016).

\subsubsection{What about MCB pricing?}

We have so far focused on the quantity of MCBs, because we are mainly interested in studying the composition shift of local government debt. A natural question to ask is whether the extra MCB issuance from provinces with aggressive bank credit in 2009 affects the prices these provinces receive, above and beyond the risk profile of individual MCBs. However, MCBs are issued and traded in a national-level corporate bond market (either the interbank market or exchanges), implying little province-level investor segmentation in these markets in China (e.g., WMPs are an important investor for MCBs). Hence, the standard asset pricing argument suggests that only the risk profiles of individual bonds-but not relative quantities of bonds-matter, as they share the same pricing kernel determined by the aggregate institutional investors in China. Of course, the 2009 Abnormal BL/GDP may help explain the cross-sectional variation of MCB spreads, if it captures some additional information about the MCB's default risk beyond those controls widely used in the existing literature.

Table 8 investigates this question. In Column 1, we first pool together all observations in 2012-2015 and regress the amount-weighted issuing yield spread of MCB over CDB bond yield with similar maturity at year and province level on various risk profiles, i.e., credit rating and bond maturity. We also include other variables from Ang et al. (2017) that potentially capture the repayment ability of local governments. We observe that credit rating stands out as the most significant driver of MCB yield spreads. ${ }^{31}$ Column 2 then includes the 2009 Abnormal BL/GDP as an extra explanatory variable, which is insignificant, with no effect on adjusted $R$-square. Columns 3 to 6 repeat the same

\footnotetext{
${ }^{31}$ Two points are worth highlighting. First, in China, the risk-free benchmark with the same maturity is the bond yield offered by CDB (rather than that of Treasury bond due to differential tax treatment). Second, credit rating stands out as the most important and significant variable that explains MCBissuance yield spread in Table 8, which is perhaps a result of some peculiar institutional practice in China. Starting in June 2010, the National Association of Financial Market Institutional Investors (the self-regulatory body of the interbank market) publishes the "guidance curve" for corporate bond yield as a function of bond rating, which is closely followed by LGFVs that are issuing MCBs in the interbank market. This anchoring explains the almost perfect one-to-one relationship between MCB ratings and their issuance yields. In unreported results, we find that rating along generates an adjusted $\mathrm{R}^{2}$ of $73 \%$ in the panel pricing regression.
} 
exercise for each year and reach the same conclusion. This null result even holds for secondary market MCB spreads. ${ }^{32}$

What do we learn from this exercise? As we emphasized, if ratings and other characteristics of MCBs already fully capture their default risk, we indeed should expect a null result for our 2009 Abnormal BL/GDP variable. This null result also suggests the supply side might play a significant role during the 2009 stimulus expansion, as higher 2009 Abnormal BL/GDP does not seem to hurt the municipal's repayment ability (conditional on other measures of local government fiscal conditions.)

\subsection{Link to Shadow Banking in China}

This section attempts to connect the non-bank debts on the liability side of local governments to the recent surging shadow banking activities in China. We approach this link from the following two angles.

The first is the off-balance-sheet Trust loans (including entrusted and trust loans). Often, these deals are arranged via banks to move the resulting loans out of their balance sheets. Since 2011, the Statistics and Analysis Department at the PBoC has started releasing the quarterly statistics of Aggregate Financing to the Real Economy, which measures the total amount of financing the real economy receives from the financial system in a given period. This measure is divided into four categories: on-balance-sheet financing (e.g., bank loans), off-balance-sheet financing (e.g., trust and entrusted loans), direct financing (e.g., bond and equity issuance), and others. Historical statistics dating back to 2002 became available in 2012, and more importantly, the PBoC started releasing these statistics at the province level in 2013.

The second angle is the so-called WMPs (i.e., Wealth Management Products), which are often sold by China's commercial banks to unsophisticated household investors at a rate higher than the deposit rate. Banks then turn around to lend the proceeds to firms, or invest them in corporate bonds or other assets, including WMPs themselves. This activity is widely recognized as a form of regulatory arbitrage, because these transactions are considered to be off-balance sheet and hence face much less regulatory restrictions than traditional banks (e.g., Acharya et al. (2017); Hachem and Song (2017a)). Another reason WMPs are considered the symbol of China's shadow banking activities is their potentially sophisticated structure, especially when financial institutions develop WMPs

\footnotetext{
${ }^{32}$ Results are not reported here but are available upon request. The sample for the regression with secondary market prices is much smaller (about $37 \%$ of sample with issuing spreads), as we need to drop MCBs without any transaction due to poor secondary market liquidity, and MCBs with special terms.
} 
together with Trust or other financial innovations. ${ }^{33}$

Trust loans and WMPs, which overlap each other to a great extent, are the largest two components of China's shadow banking sector. According to the PBoC, the notional outstanding of trust loans and WMPs accout for $73 \%$ of the shadow banking sector in China. ${ }^{34}$ Therefore, understanding the role played of Trust loans and WMPs in local government financing activities, including the issuance of MCBs, is crucial for understanding the fast growth of China's shadow banking sector after 2012.

\subsubsection{Shadow banking activities and local government non-bank debt}

Panel A of Figure 7 plots the new Trust loans and increase of WMPs over 2004-2016, together with new bank loans, all scaled by GDP. Both Trust loans and WMPs are growing much faster than the GDP growth starting in 2012, a pattern consistent with the mechanism proposed by this paper. At the end of 2015, the magnitude of these two shadow banking activities becomes comparable to the traditional on-balance-sheet credit extended by banks. ${ }^{35}$

Connecting China's shadow banking activities back to local government debt, Panel $\mathrm{B}$ of Figure 7 plots the fraction of local government non-bank debt, which is the sum of MCB, munibond, and Trust in Figure 4, relative to the sum of three items in the Aggregate Financing to the Real Economy that proxy for shadow banking activities in China: Trust loans (trust and entrusted loans) as mentioned above, undiscounted bankers' acceptances, and corporate bonds. ${ }^{36}$ We observe a steady growth of local government non-bank debt as a fraction of the shadow banking balance in China, starting from a

\footnotetext{
${ }^{33}$ See "Four Fresh Worries About China's Shadow Banking System" by Bloomberg, September 7, 2016. Note that because WMPs do not represent the ultimate financing received by the real sector, it is not one of the items of the Aggregate Financing to the Real Economy mentioned above.

${ }^{34}$ As of the end of 2017, the off-balance-sheet non-guaranteed WMP outstanding was RMB 22.2 trillion, the trust loan outstanding was RMB 21.9 trillion, and the notional outstanding of asset management plans from securities companies and mutual fund subsidaries was RMB 16.4 trillion (http://www.scio.gov.cn/xwfbh/gbwxwfbh/xwfbh/rmyh/Document/1628765/1628765.htm). Another estimate by Moody's attributes $74 \%$ of China's shadow banking to trust loans (34\%) and WMPs (40\%); see "China Takes 'More Flexible Way' on Wealth Products Rule Changes" by Bloomberg, July $23,2018$.

${ }^{35}$ After 2013, we observe some sharp decline of new Trust loans but a rapid rise of new WMPs. This is a result of substitution from Trust loans toward WMPs after the China Banking Regulatory Commission tightened the regulation on trust products in 2014 (the 99th Document "Directive Opinions on the Regulation of Trust Companies' Risk Management," May 8, 2014, by the CBRC), and it is interesting to see the similar magnitude between the decline of Trust and the rise of WMPs in Panel A post 2014.

${ }^{36}$ Undiscounted bankers' acceptances, which are only about $2.5 \%$ of Aggregate Financing to the Real Economy (5.2\% of GDP) in 2016, represent contingent credit to the real sector, in the sense that firms can use bankers' acceptances as collateral to obtain loans from banks (which then will be recorded as on-balance bank loans). We also include aggregate outstanding corporate bonds in our calculation, which are about $11.5 \%$ of Aggregate Financing to the Real Economy (24.1\% of GDP) in 2016, as MCBs in local government debt are counted as part of corporate bonds.
} 

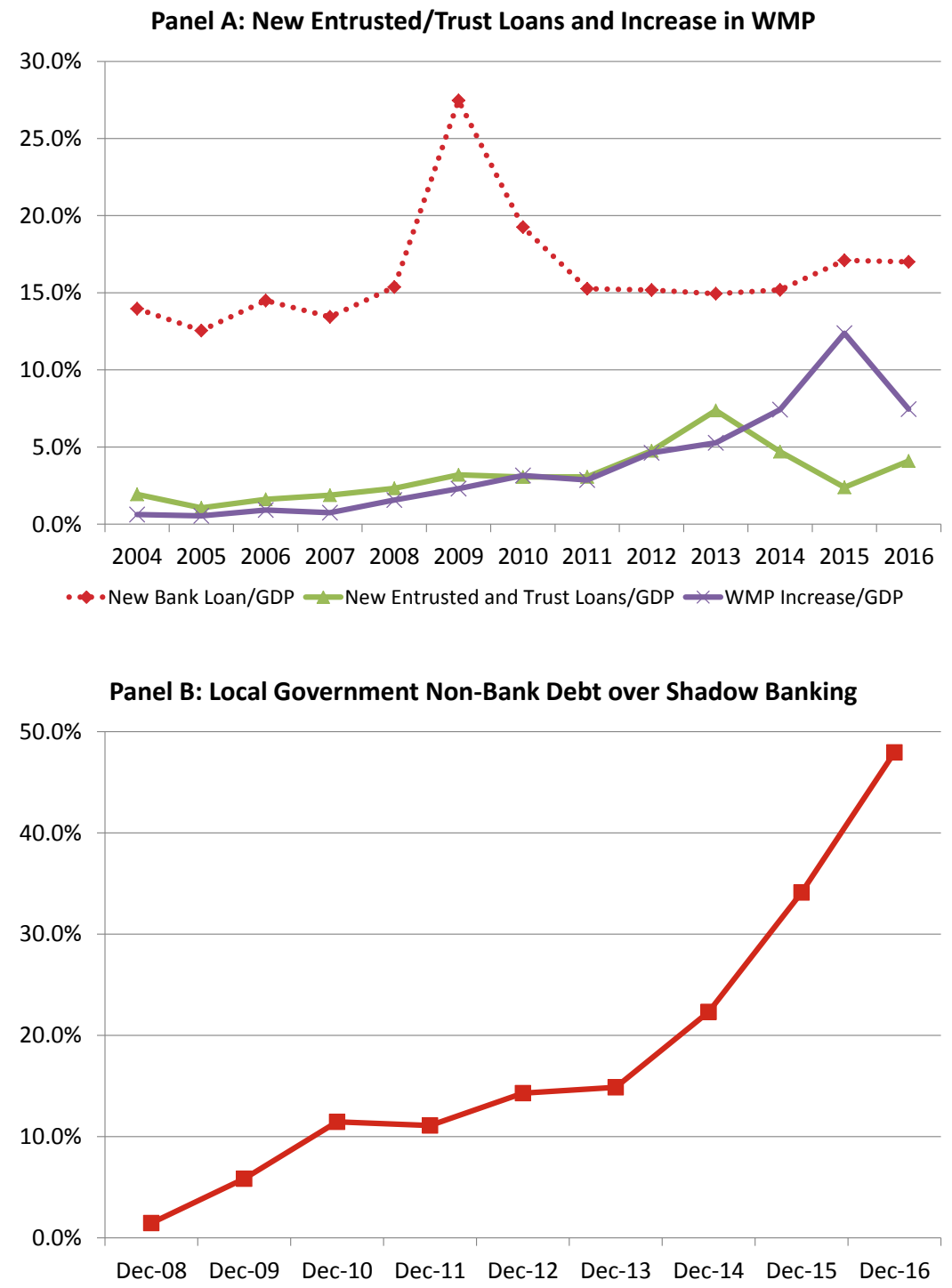

Figure 7: Shadow Banking Activities and Local Government Non-bank Debt. Panel A plots new trust loans (entrusted and trust loans) and change in WMPs over GDP from 2004 to 2016. The aggregate new bank loans over GDP is also plotted for comparison. Panel B plots local government non-bank debt balance as a fraction of China's shadow banking balance from 2008 to 2016. Local government non-bank debt is the sum of MCBs, munibonds, and local government trust balance. Shadow banking balance is proxied by three items in Aggregate Financing to the Real Economy, including trust loans (trust and entrusted loans), undiscounted bank's acceptable bills, and corporate bonds. The annual WMP balance data are from China Commercial Banks' Wealth Management Products Annual Report issued by China Banking Wealth Management Registration System. The Aggregate Financing to the Real Economy by category data are from the PBoC. 
negligible $1.5 \%$ in 2008 to $22 \%$ in 2014 and $48 \%$ in 2016. This finding suggests that local government non-bank debt is crucial to understand the recent surge of shadow banking activities in China.

\subsubsection{Bank loan wanes and trust loans waxes}

Panel A in Figure 7 presents the similar time-series pattern of "bank loan down and shadow banking up" when stepping outside the box of local governments. We further perform a cross-sectional test in this subsection, following the same idea as in Section 4 but replacing $\mathrm{MCB}$ issuance by new entrusted loans at the corresponding province (which might go to LGFVs). Because we do not have provincial information for entrusted loans before 2013, and because entrusted loans were tiny before 2008 anyway, we take the entrusted loans in future years (2013-2015) as "abnormal" and scale them by the corresponding provincial GDP directly as the dependent variables.

Table 9 shows that the stimulus-loan-hangover effect holds for entrusted loans, both each year and over the period of 2013-2015, implying that areas with more stimulus bank loans in 2009 ended up engaging with more entrusted loans in later years. The magnitude identified from this regression is greater, suggesting entrusted loans are more important than MCBs as financing tools at the economy-wide level. Column 6 further provides a placebo test, which shows that the 2009 Abnormal BL/GDP cannot explain the cross-sectional pattern of new bank loans in later years. This finding is consistent with the premise of our paper, which says that China's credit policy reverted back to normal in later years and induced shadow banking to fill the gap.

We perform the cross-sectional test for entrusted loans, not trust loans. Magnitudewise, over the past decade, each year more new entrusted loans than new trust loans are extended. At the end of 2016, the newly issued entrusted loans are about RMB 2.3 trillion (3.1\% of GDP), compared to trust loans being RMB 0.9 trillion (1.2\% of GDP). But we pick entrusted loans for our cross-sectional test for a deeper economic reason. As we discussed at the beginning of Section 4, the way these statistics are reported is that the region of a trust loan is where the trust gets financed (i.e., location of source), not where the trust funds go (i.e., location of use). ${ }^{37}$ Our mechanism relies on identifying the location of fund use, and hence this source-use mismatch of locations is devastating for our purpose. Entrusted loans suffer the same problem, but it is much less severe,

\footnotetext{
${ }^{37}$ For trust data from Aggregate Financing to the Real Economy, we checked with the Statistics and Analysis Department at the PBoC and found that they collected the data from the reporting of local CBRCs, which receive the trust prospectus information from trust companies that are geographically located in a province. As a result, the provincial trust data only reflect the fund-raising location instead of the fund-using location.
} 
because entrusted loans are firm-to-firm credit, and these firms tend to be intermediated by the same bank. Given that banks typically finance local firms only (easier monitoring, less information asymmetry), the location of source should be more correlated with the location of use. Indeed, Allen et al. (2018) find that entrusted loans tend to be provided to firms within the same area in China.

\subsubsection{WMPs invested in MCB via interbank market}

MCBs, as one type of corporate bond, are mostly traded by qualified financial institutions (including banks, mutual funds, insurance companies, etc.) in China's interbank market. We now give a brief institutional background on this financial market, which has grown rapidly in recent years and had become the third largest in the world by May 2016, behind only the U.S. and Japan (Borst (2016)).

Two major classes of bonds are traded in China's interbank market. Government bonds and bonds issued by policy banks are considered riskless and are often called "interest rate bonds," whereas corporate bonds issued by non-financial firms are called "credit bonds" for their potential credit risk. MCBs become interesting because they sit between these two categories. From their name, they have the feature of being "interest rate bonds," which enjoy the implicit backing of the corresponding local government (thus the word municipal), but in a strict legal sense, they are issued by the LGFV entities, which are just corporations like other credit-bond issuers (thus the word corporate). What is more, MCBs represent a significant fraction of credit bonds in China: they accounted for $36.3 \%$ of total credit bonds at the end of 2016. This fraction has been rising dramatically over the past several years, from only $12.8 \%$ at the end of 2008 . The fast growth of MCBs is likely to be explained by the stimulus-loan-hangover effect.

WMPs, sold by commercial banks in China, are widely reported to be aggressively investing in MCBs. Thanks to the hide-and-seek games between the regulators and financial institutions (outside and inside the interbank market), the list of qualified participants in China's bond market has been in flux over the past few years. In February 2014, in response to the rapidly growing demand of investment in the interbank market, the $\mathrm{PBoC}$ opened the interbank market access to 16 large commercial banks for their own WMPs. But unqualified smaller banks can easily circumvent this regulation by engaging with the "counterpart" business with qualified large banks. Two years later in May 2016, facing more and more complicated financing structures created to channel WMPs into the interbank market, the $\mathrm{PBoC}$ removed the previous restrictions and allowed all qualified institutional investors, including WMPs and trust companies, to participate directly in the interbank market and invest in corporate bonds. This deregulation propelled another 


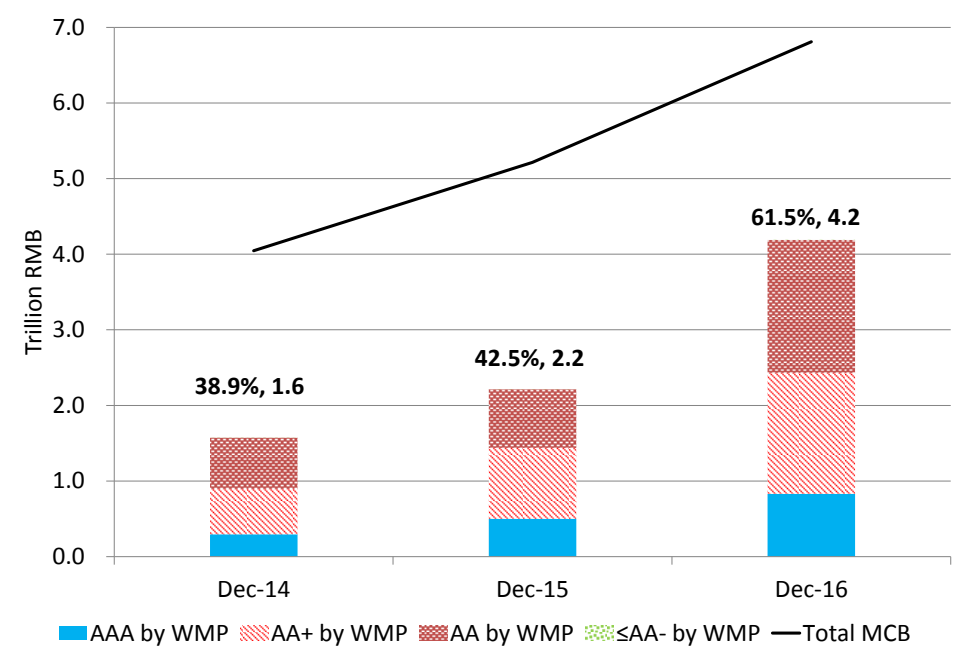

Figure 8: Wealth Management Products Investment in Municipal Corporate Bonds, from 2014 to 2016. The solid line plots the total MCB balance, and bars represents WMPs invested in MCBs with various ratings. The percentage and RMB value (trillion) of MCBs held by WMPs are given above the bars. The MCB data are from WIND, and the WMP investment data are from China Commercial Bank Wealth Management Products Annual Report issued by China Banking Wealth Management Registration System. More estimation details are in Appendix C.

round of expansion of WMPs and "innovative" trading strategies, as WMPs started Repo transactions with embedded leverage for high returns. ${ }^{38}$ This investment behavior soon caught the attention of many economists and regulators, triggering another round of regulation by the $\mathrm{PBoC}$ to include the off-balance-sheet WMPs in its Macro Prudential Assessment (MPA) system in early 2017.

Gauging the risk exposure of shadow banking activities is always a challenge, and there is no difference for measuring risk exposure of WMPs, which in principal could invest in everything, including other WMPs. Fortunately, since 2014, the China Banking Wealth Management Registration System has started issuing annual official statistics on WMPs. Combining these annual reports together with the rating information of MCB, we estimate the MCB holdings by WMPs, which are plotted in Figure 8 together with the corresponding MCB outstanding balance.

Figure 8 shows that WMPs are mainly investing in high-quality MCBs, as almost all of them are above AA-rating. The official reports suggest that about $40 \%$ of MCBs were held by WMPs by the end of 2014; this fraction rose to more than $60 \%$ by the end of 2016. Nevertheless, these numbers are quite likely to represent an underestimation of the

\footnotetext{
${ }^{38}$ https://www.bloomberg.com/news/articles/2016-09-07/four-fresh-worries-about-china-s-shadowbanking-system.
} 
extent to which WMPs are investing in MCB, because before the May 2016 deregulation, managers of WMPs (raised by some small banks) commonly invested these funds in some Trusts, which lend the money to another bigger bank that then eventually invests in MCB. From reading the way the statistics are reported, the Annual Report ignores this indirect exposure of WMPs in MCB (hence introducing a downward bias of our estimate). One estimate from an anecdotal but trustworthy source is that about $70 \%$ of MCBs are invested by WMPs.

\subsubsection{Corporate bond and shadow banking in China}

Corporate bonds are commonly viewed as transparent financial market instruments, and financing through corporate bonds is not classified as shadow banking activity. However, it is not the case in China. WMPs, the most important component of the shadow banking sector, are not the ultimate user of funds and thus are not included in the PBoC's Aggregate Social Financing to the Real Economy. Instead, WMPs channel a significant amount of funds into China's bond market. Lei et al. (2018) find that RMB 7 trillion, or $38 \%$, out of the RMB 18 trillion outstanding balance of corporate bonds is funded by WMPs at the end of 2017; this number was $40 \%$ in 2016. More importantly, as explained toward the end of the previous section, these numbers are likely to be biased downward.

The trend of the increasing share of bond market funding being channelled through WMPs and thus the fast growth of China's bond market after 2012 was initially encouraged by regulators. Worried about WMPs' increasing investments in non-standard debt assets that were essentially a disguised form of on-the-balance-sheet loans of the WMP issuing bank, the CBRC issued the "Document 8" in March 2013 restricting WMPs' investment in non-standard debt assets, which pushed WMPs to allocate more funds toward standard debt assets such as corporate bonds. A few years later, the asset management industry, mainly composed of WMPs and trust loans, grew into a giant with sophisticated multi-layer structures, essentially working as shadow intermediaries that channel funds from capital markets to the real economy.

However, the growing complexity of the shadow banking sector and the increased number of corporate bond defaults in 2015 and 2016 raised a red flag for their potential systemic risk and resulting instability of the economy. Starting in 2017, the central government made regulatory changes in the asset management industry, including deleveraging and tight restriction on WMP issuance. Specifically, the new asset management regulatory framework was taken into discussion in February 2017, and the "Guidance Opinions Concerning Standardization of Asset Management Operations by Financial Institutions" was released to solicit public opinion in November of that year. Finally, on 
April 27, 2018, the new set of regulations on the asset management industry was officially launched, aiming to discipline the shadow banking sector by the end of 2020 .

The policy change has a profound impact on China's shadow banking sector. The outstanding WMP is RMB 29.54 trillion as of the end of 2017, which is similar to 29.05 trillion in 2016 (by contrast, the WMP balance was 23.67 trillion at the end of 2015). Consistent with WMPs as the major funding channel of corporate bonds, during the same period, the Chinese corporate bonds sector shrank dramatically in 2017: the net aggregate social financing from corporate bonds was RMB 0.45 trillion in 2017 compared to RMB 3.04 trillion in 2016. We see a smiliar pattern for the MCB market: the percentage of MCBs held by WMPs dropped to $59.4 \%$ in 2017 from $61.5 \%$ in 2016, and the RMB value of WMPs' holding in MCBs only increased slightly to 4.23 trillion from 4.19 trillion. Overall, the regulatory restriction on China's shadow banking activities (especially WMPs) has a direct effect on the corporate bond market, supporting the perspective that the relatively transparent corporate bond sector is indeed an integrated part of the shadow banking system in China. ${ }^{39}$

\section{Discussions and Concluding Remarks}

This paper paints a broad picture that connects the 2007/08 financial crisis in the US, the 2009 four-trillion-yuan stimulus loans in China, and the surging shadow banking activities in China after 2012. Although both WMPs and Trust loans existed in China's financial markets before 2008, and increased slightly during the period of the 2009 stimulus plan, our perspective highlighting the stimulus-loan-hangover effect helps us understand why these activities experienced "barbarous growth" after 2012.

We conclude this paper by providing discussions on the potential systemic risk of local government debt, some interesting political economics on the marketization of the financial system, and the process of interest rate liberalization in China.

Systemic risk of local governments debt. The potential systemic risk of China's local-government debt is an extremely important question of broad interest, but it is not the focus of this paper. Local governments have been relying heavily on land sales to balance their budget (e.g., Zhang and Barnett (2014); Ambrose et al. (2015)), which is unlikely to be sustainable in the long run. Of course, the issue is more than the simple default risk. These debts are backed by governments at different authority levels, explic-

\footnotetext{
${ }^{39}$ Bian et al. (2018) find that even the more transparent stock market is affected by the shadow banking sector, consistent with the observation in Ehlers et al. (2018) that funds raised by WMPs and trust loans are channelled to the equity market to some extent.
} 
itly or implicitly. The market participants, whether those naive WMP investors who do not even know what they are buying or sophisticated bond fund managers who study the default risk of LGFVs extensively, all have "bail-out" expectations, implying that either banks (which sold WMPs) or local governments (which sold MCBs) are bearing the loss ultimately. In 2015, the Ministry of Finance started the "swap program" that allows local governments to issue munibonds to replace their maturing "qualified" debt, which largely excludes the "contingent bailout liability" in Table 1. The widespread understanding is that these munibonds are ultimately fully backed by the central government, which have plenty of resources to absorb the losses. This significantly reduces, though far from eliminates, the uncertainty of the local governments' repayment ability and the default risk of MCBs. ${ }^{40}$

On the other hand, the potential default risk of local governments could be systemic because, as explained, China's local government debts are either hidden on the banks' off-balance sheets, such as MCBs through WMPs, or even directly sitting on their onbalance sheets. Intriguingly, about $87 \%$ of munibonds with full government guarantees were directly held by banks as of 2016. Gao et al. (2018) provide direct evidence of LGFVs defaulted on their bank loans before 2014. The situation is likely to be worse after 2014, as the "swap program" mentioned above has severed certain MCBs from explicit government guarantees, and it is widely believed that unprofitable LGFVs will experience difficulties in repaying their maturing MCBs in the near term. This is exactly why market participants and regulators are keeping a close eye on the recent development of the local government debt in China.

The political economics of regulation and market forces. Over the past 40 years, China has undoubtedly made tremendous progress in building a market-based economy. Unfortunately, due to the history of being an economy with central planning, almost all economic activities, including LGFVs and MCBs, are linked back to certain regulations and/or the intentions of regulators.

We emphasize that regulations themselves are endogenous, and mostly are responses to the underlying market forces. Consider the evolution of regulations and the actual implementations when dealing with the explosive growth of debt taken by LGFVs after 2009. In June 2010, the State Council issued the No. 19 Document on LGFVs, underscoring the importance of regulating and monitoring the mounting debt raised by LGFVs. The market responded by little MCB issuance during 2010-11, as shown in

\footnotetext{
${ }^{40}$ One upper-bound estimate of the default risk is from the "contingent bailout liability," which consists of about $24 \%$ of total debt standing at mid-2013 (Table 1). The "bail-out" expectation can be fulfilled as long as local governments themselves are able to cover the potential losses of these "contingent bailout liability," which is unqualified for the "swap program" of munibonds.
} 
Figure 5. But MCBs grew even faster starting in 2014. Why? It is not because the regulators deemed the LGFVs to be safer after 2014. In fact, as mentioned in Section 2.2.2, the State Council-issued No. 43 Document in September 2014 prohibited local governments from raising debt via LGFVs, and ordered local governments to swap existing debt with more transparent munibonds. Implementing the swap program has been far from smooth. The budget of munibonds for 2015 was preapproved at the end of 2014, and in 2015, it became apparent that the preapproved amount was not enough to absorb all the refinancing needs of LGFVs. Beijing in turn issued other "conflicting" regulation changes that aimed to enable the LGFVs to borrow via MCBs. ${ }^{41}$

Our paper delivers a fresh view on why regulators successfully suppressed MCB growth around 2010 but somehow failed to do so after 2013: LGFVs had to roll over their bank loans due around 2013 and 2014, a market force that demanded full respect and had to be released one way or another. Putting these debts back into the banks' balance sheets and finding support from non-bank (or even shadow banking) financing sources requires some trade-off, and Beijing seems to have picked the latter.

Interest rate liberalization. Our paper offers a perspective on understanding the pace of interest rate liberalization in China. China's interest rate liberalization can be traced back to the establishment of the interbank market in 1996, which in early 2007 launched Shanghai Interbank Offered Rate (Shibor), serving as the benchmark rate in China's capital market. Banks' lending rates started a slow reform around 1998-99, and experienced several aggressive deregulating steps thanks to China joining WTO in 2001. Similar to other developed countries such as the U.S. and Japan, deposit rate liberalization is the last step of the marketization of interest rates in China. Although the lower limit of the deposit rate was removed in 2004, the upper limit was tightly controlled until 2012, when banks were allowed to raise their deposit rates up to 1.1 times the base rate set by the PBoC. The upper limit was further raised to 1.2 times in 2014 and 1.5 times in 2015, and fully removed in October 2015. Beijing also established the deposit insurance scheme in May 2015, aiming to provide the same level-playing field for small- and medium-sized banks against their Big-Four peers.

We highlight that the pace of the liberalization process has taken up tremendously since 2012, especially for the deposit rate liberalization. From the perspective of our paper, such acceleration in liberalization can be thought of an unintended (but good)

\footnotetext{
${ }^{41}$ For instance, the interbank market relaxed the restrictions on eligible LGFVs to issue MCB in early 2015; similar relaxations were reflected in a series of documents released by the National Development and Reform Commission (the regulatory body of MCBs traded in the interbank market) and Ministry of Finance. For a complete list of regulations and documents released after 2014, see "MCB Regulation, Review, and Outlook" by Qiming Liu in PengYuan Research, February 2016.
} 
consequence of the 2009 stimulus plan. The resulting growth of WMPs starting 2012 offered households an attractive savings vehicle, with market-based interest rates that are much higher than those offered by bank deposits. This imposes an unprecedented threat to the traditional banking sector, which has been heavily subsidized by cheap deposits for more than half a decade. Facing heavy legacy regulations, individual banks competed with each other by selling WMPs to households in order to expand their off-balance-sheet activities. ${ }^{42}$ On the positive side, this process benefits not only households, but also those small and medium-sized banks that are now able to compete with the Big Four banks in China. However, these off-balance-sheet activities seem to be overly aggressive, and regulators realize that the market force has unleashed itself fully so that it is the right timing to expedite the process of interest rate liberalization.

\footnotetext{
${ }^{42}$ Acharya et al. (2017) and Hachem and Song (2017a) offer interesting studies on competition within the banking sector as well as its implications on WMPs issuance before and around 2009. For later years, see a Financial Times article "China takes step to financial reform" by Anderlini and Hook, dated July 19, 2013.
} 


\section{References}

Acharya, V Viral, Jun Qian, and Zhishu Yang, 2017, In the shadow of banks: wealth management products and issuing banks' risk in China, Working paper.

Allen, Franklin, Xian Gu, Jun Qian, and Yiming Qian, 2017, Implicit guarantee and shadow banking: the case of trust products, Working paper.

Allen, Franklin, Yiming Qian, Guoqian Tu, and Frank Yu, 2018, Entrusted loans: A close look at China's shadow banking system, Journal of Financial Economics, forthcoming.

Ambrose, Brent W, Yongheng Deng, and Jing Wu, 2015, Understanding the risk of China's local government debts and its linkage with property markets, Working paper.

Amstad, Marlene, and Zhiguo He, 2018, Chapter 6: Interbank System, Handbook of China's Financial System, edited by Marlene Amstad, Guofeng Sun and Xiong Wei .

An, Ping, and Mengxuan Yu, 2018, Neglected part of shadow banking in China, International Review of Economics $\&$ Finance.

Ang, Andrew, Jennie Bai, and Hao Zhou, 2017, The great wall of debt: real estate, corruption, and Chinese local government credit spreads, Working paper.

Bai, Chong-En, Chang-Tai Hsieh, and Zheng(Michael) Song, 2016, The long shadow of a fiscal expansion, Brookings Papers on Economic Activity 60, 309-327.

Bian, Jiangze, Zhiguo He, Kelly Shue, and Hao Zhou, 2018, Leverage-induced fire sales and stock market crashes, Working Paper .

Borst, Nicholas, 2016, China's bond market: Larger, more open, and riskier, Technical report, Federal Reserve Bank of San Francisco.

Chen, Hui, Zhuo Chen, Zhiguo He, Jinyu Liu, and Rengming Xie, 2018a, Pledgibility and asset prices: Evidence from the chinese corporate bond markets, Working Paper .

Chen, Kaiji, Jue Ren, and Tao Zha, 2018b, The nexus of monetary policy and shadow banking in China, American Economic Review, forthcoming.

Chen, Long, and Chongqing $\mathrm{Gu}, 2012$, The impact of loans by local government financing vehicals on bank valuations, Memo, CKGSB. 
Cong, Will, Haoyu Gao, Jacopo Ponticelli, and Xiaoguang Yang, 2018, Credit allocation under economic stimulus: Evidence from China, Working paper, Booth School of Business, University of Chicago.

Deng, Yongheng, Randall Morck, Jing Wu, and Bernard Yeung, 2015, China's pseudomonetary policy, Review of Finance 19, 55-93.

Diamond, Douglas W., 1991, Debt maturity structure and liquidity risk, Quarterly Journal of Economics 106, 709-737.

Diamond, Douglas W., and Zhiguo He, 2014, A theory of debt maturity: The long and short of debt overhang, The Journal of Finance 69, 719-762.

Ehlers, Torsten, Steven Kong, and Feng Zhu, 2018, Mapping shadow banking in China: structure and dynamics, BIS Working Paper.

Gao, Haoyu, Hong Ru, and Dragon Yongjun Tang, 2018, Subnational debt of China: The politics-finance nexus, Working paper, City University of Hong Kong and Nanyang Technological University and The University of Hong Kong.

Hachem, Kinda, 2018, Shadow banking in China, Annual Review of Financial Economics, forthcoming.

Hachem, Kinda, and Zheng Michael Song, 2017a, Liquidity regulation and unintended financial transformation in china, Working paper.

Hachem, Kinda, and Zheng Michael Song, 2017b, Liquidity rules and credit booms, Working paper.

He, Qing, Liping Lu, and Steven Ongena, 2018, Who gains from credit granted between firms? Evidence from inter-corporate loan announcements made in China, Working Paper .

He, Zhiguo, and Wei Xiong, 2012, Rollover risk and credit risk, The Journal of Finance 67, 391-429.

Huang, Yi, Marco Pagano, and Ugo Panizza, 2016, Public debt and private firm funding: Evidence from Chinese cities, Working paper, The Graduate Institute (Geneva) and University of Naples Federico II. 
Jia, Junxue, Xiaoying Zhang, and Jing Ning, 2017, The influence of multi-dimension promotion incentives on local government borrowing behavior, China Industrial Economics (in Chinese) 5-23.

Kroeber, Arthur, 2016, China's Economy: What Everyone Needs to Know (Oxford University Press).

Lei, Katherine, George Cai, Stephen Tsui, Jemmy S Huang, Haibin Zhu, Marvin M Chen, and Soo Chong Lim, 2018, China financials: embracing a rise in corporate bond defaults, J.P. Morgan Asia Pacific Corporate Research .

Li, Hongbin, and Li-An Zhou, 2005, Political turnover and econmomic performance: the incentive role of personnel control in china, Journal of Public Economics 89, 17431762.

Liu, Laura Xiaolei, Yuanzhen Lyu, and Fan Yu, 2017, Implicit government guarantee and the pricing of Chinese LGFV debt, Working paper.

Ru, Hong, 2018, Government credit, a double-edged sward: Evidence from the China Development Bank, The Journal of Finance 73, 275-316.

Song, Zheng (Michael), K. Storesletten, and F. Zilibotti, 2011, Growing like China, American Economic Review 101, 196-233.

Tan, Zhibo, and Li-An Zhou, 2015, Officials' tenure, credit cycles and investment cycles, Journal of Financial Research (in Chinese) 80-93.

Wang, Hao, Honglin Wang, Lisheng Wang, and Hao Zhou, 2016, Shadow banking: China's dual-track interest rate liberalization, Working paper.

Zhang, Yuanyan, and Steven A Barnett, 2014, Fiscal vulnerabilities and risks from local government finance in China, Working paper. 


\section{Table 1: Local Government Debts from NAO Reports}

This table reports sources of local government debt from two reports issued by the National Auditing Office of China. Panel A (B) reports the auditing results as of December 31, 2010 (June 30, 2013).

Panel A: Local government debt balance as of December 31, 2010 (billion RMB)

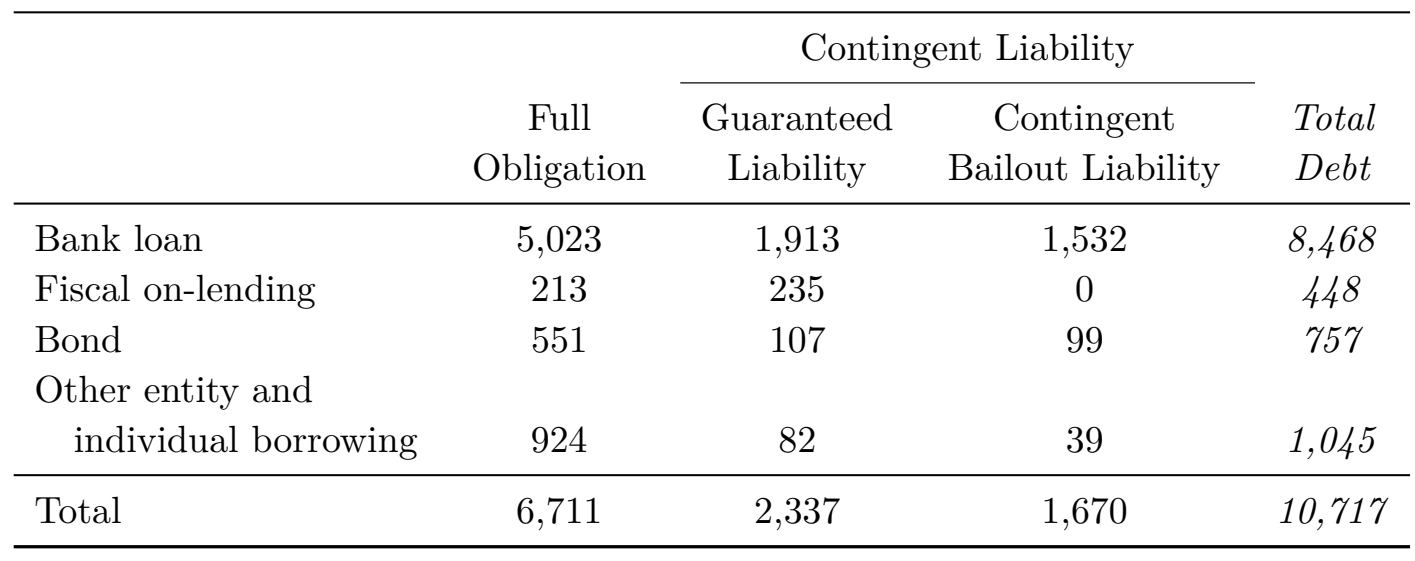

Panel B: Local government debt balance as of June 30, 2013 (billion RMB)

\begin{tabular}{lcccc}
\hline & & \multicolumn{2}{c}{ Contingent Liability } & \\
\cline { 3 - 4 } & $\begin{array}{c}\text { Full } \\
\text { Obligation }\end{array}$ & $\begin{array}{c}\text { Guaranteed } \\
\text { Liability }\end{array}$ & $\begin{array}{c}\text { Contingent } \\
\text { Bailout Liability }\end{array}$ & Total \\
& 5,525 & 1,909 & 2,685 & 10,119 \\
\hline Bank loan & 1,215 & 47 & 215 & 1,476 \\
Build \& Transfer & 1,166 & 167 & 512 & 1,846 \\
Bond & 615 & 49 & 0 & 664 \\
$\quad$ MuniBond & 459 & 81 & 343 & 883 \\
Corporate bond (MCB) & 58 & 34 & 102 & 194 \\
Mid-term note (MCB) & 12 & 1 & 22 & 36 \\
$\quad$ Short-term bill (MCB) & 778 & 9 & 70 & 857 \\
Accounts payable & 762 & 253 & 410 & 1,425 \\
Trust & & & & \\
Other entity and & 668 & 55 & 116 & 839 \\
$\quad$ individual borrowing & 327 & 1 & 48 & 376 \\
Construction loan & & & & \\
Other financial & 200 & 31 & 0 & 337 \\
$\quad$ institution borrowing & 133 & 171 & 137 & 303 \\
Fiscal on-lending & 75 & 19 & 39 & 832 \\
Capital lease & 37 & 4 & 4,339 & 17,891 \\
Other fund raising & 10,886 & 2,666 & &
\end{tabular}


Table 2: Summary Statistics

This table reports the summary statistics of key variables for provincial municipal corporate bond $(\mathrm{MCB})$ issuance and economic conditions. Panels A and B report the summary statistics of 2012-2015 raw values and the abnormal values over the 2004-2008 average for various variables. Variables include MCB/GDP, MCB for repayment of bank loans over GDP, MCB for investment over GDP, MCB for other purpose over GDP, 2009 bank loans over GDP, 2008Q1-Q3 bank loans over GDP, fiscal deficit over GDP (FD/GDP), fixed-asset investment over GDP (FAI/GDP), land sale over fiscal revenue (LS/FR), GDP growth ( $\triangle$ GDP ), and entrusted loans over GDP (EL/GDP).

Panel A: Summary Statistics of Variables' Raw Values

\begin{tabular}{lcccccccc}
\hline & Obs & Mean & SD & Min & P25 & Median & P75 & Max \\
\hline MCB/GDP & 120 & 0.022 & 0.016 & 0.000 & 0.011 & 0.016 & 0.028 & 0.083 \\
MCB_repay/GDP & 120 & 0.006 & 0.007 & 0.000 & 0.001 & 0.004 & 0.008 & 0.037 \\
MCB_inv/GDP & 120 & 0.011 & 0.006 & 0.000 & 0.006 & 0.010 & 0.014 & 0.035 \\
MCB_other/GDP & 120 & 0.000 & 0.001 & 0.000 & 0.000 & 0.000 & 0.000 & 0.009 \\
2009 BL/GDP & 30 & 0.275 & 0.082 & 0.158 & 0.219 & 0.259 & 0.330 & 0.452 \\
2008Q1-Q3 BL/GDP & 30 & 0.151 & 0.051 & 0.076 & 0.115 & 0.143 & 0.190 & 0.239 \\
FD/GDP & 120 & 0.127 & 0.100 & 0.014 & 0.045 & 0.117 & 0.150 & 0.529 \\
FAI/GDP & 120 & 0.794 & 0.220 & 0.254 & 0.684 & 0.821 & 0.917 & 1.301 \\
LS/FR & 120 & 0.173 & 0.118 & 0.035 & 0.096 & 0.144 & 0.194 & 0.650 \\
$\Delta$ GDP & 120 & 0.089 & 0.038 & -0.007 & 0.066 & 0.089 & 0.113 & 0.202 \\
EL/GDP & 90 & 0.033 & 0.026 & -0.018 & 0.017 & 0.027 & 0.041 & 0.142 \\
\hline
\end{tabular}

Panel B: Summary Statistics of Variables' Abnormal Values

\begin{tabular}{lcccccccc}
\hline & Obs & Mean & SD & Min & P25 & Median & P75 & Max \\
\hline MCB/GDP & 120 & 0.021 & 0.016 & -0.002 & 0.010 & 0.016 & 0.027 & 0.081 \\
MCB_repay/GDP & 120 & 0.006 & 0.007 & 0.000 & 0.001 & 0.004 & 0.008 & 0.037 \\
MCB_inv/GDP & 120 & 0.010 & 0.006 & -0.002 & 0.005 & 0.010 & 0.014 & 0.035 \\
MCB_other/GDP & 120 & 0.000 & 0.001 & 0.000 & 0.000 & 0.000 & 0.000 & 0.009 \\
2009 BL/GDP & 30 & 0.164 & 0.050 & 0.083 & 0.129 & 0.158 & 0.190 & 0.270 \\
2008Q1-Q3 BL/GDP & 30 & 0.041 & 0.029 & -0.020 & 0.022 & 0.032 & 0.060 & 0.101 \\
FD/GDP & 120 & 0.042 & 0.046 & -0.007 & 0.013 & 0.030 & 0.055 & 0.265 \\
FAI/GDP & 120 & 0.301 & 0.177 & -0.111 & 0.204 & 0.307 & 0.424 & 0.799 \\
LS/FR & 120 & 0.001 & 0.075 & -0.147 & -0.043 & -0.013 & 0.024 & 0.411 \\
\hline
\end{tabular}


Table 3: The Effects of 2009 Abnormal Bank Loan on Future Municipal Corporate Bond Issuance, Year-by-Year Regressions

This table reports the year-by-year regressions of 2012-2015 provincial municipal corporate bond (MCB) issuance on 2009 bank loan. The dependent variable is the abnormal MCB issuance scaled by GDP in years 2012-2015 compared to the average value between 2004 and 2008. Annual MCB issuance at the provincial/regional level are aggregated over individual MCB bonds. The independent variable is the abnormal new bank loan scaled by GDP in 2009 compared to the average value between 2004 and 2008. Panels A and B report the cross-regional and the cross-provincial results, respectively. Panel $\mathrm{C}$ reports the cross-provincial results with control variables, including abnormal fiscal deficit (FD) scaled by GDP, abnormal fixed-asset investment (FAI) scaled by GDP, abnormal local government land sale income (LS) scaled by fiscal revenue (FR), GDP growth, and the corruption index constructed by Ang et al. (2016). Data about bank loans are obtained from the PBoC, data about MCBs are obtained from WIND, and data about control variables are obtained from the National Bureau of Statistics of China. Heteroscedasticity consistent $t$-statistics are reported in parentheses. $* * *, * *$, and $*$ indicate significance at the $1 \%, 5 \%$, and $10 \%$ levels, respectively.

Panel A: 2009 bank loan and 2012-2015 MCB issuance, regional

\begin{tabular}{lcccc}
\hline & $(1)$ & $(2)$ & $(3)$ & $(4)$ \\
& $\mathrm{MCB}_{2012}$ & $\mathrm{MCB}_{2013}$ & $\mathrm{MCB}_{2014}$ & $\mathrm{MCB}_{2015}$ \\
\hline 2009 BL/GDP & $0.11^{* * *}$ & $0.11^{* *}$ & $0.22^{* * *}$ & $0.24^{* *}$ \\
& $(2.66)$ & $(2.24)$ & $(3.29)$ & $(2.52)$ \\
Constant & -0.00 & -0.00 & -0.01 & -0.02 \\
& $(-0.46)$ & $(-0.47)$ & $(-0.65)$ & $(-0.99)$ \\
Observations & 7 & 7 & 7 & 7 \\
Adj. R & 0.42 & 0.35 & 0.44 & 0.46 \\
\hline
\end{tabular}

Panel B: 2009 bank loan and 2012-2015 MCB issuance, provincial

\begin{tabular}{lcccc}
\hline & $(1)$ & $(2)$ & $(3)$ & $(4)$ \\
& $\mathrm{MCB}_{2012}$ & $\mathrm{MCB}_{2013}$ & $\mathrm{MCB}_{2014}$ & $\mathrm{MCB}_{2015}$ \\
\hline 2009 BL/GDP & 0.11 & $0.13^{* * *}$ & $0.20^{* * *}$ & $0.15^{* *}$ \\
& $(1.55)$ & $(2.61)$ & $(3.45)$ & $(2.05)$ \\
Constant & -0.00 & -0.01 & -0.00 & 0.00 \\
& $(-0.15)$ & $(-0.89)$ & $(-0.50)$ & $(0.01)$ \\
Observations & 30 & 30 & 30 & 30 \\
Adj. R & 0.10 & 0.31 & 0.34 & 0.17 \\
\hline
\end{tabular}


Table 3 continued

Panel C: 2009 bank loan and 2012-2015 MCB issuance, with controls

\begin{tabular}{lcccc}
\hline & $(1)$ & $(2)$ & $(3)$ & $(4)$ \\
& $\mathrm{MCB}_{2012}$ & $\mathrm{MCB}_{2013}$ & $\mathrm{MCB}_{2014}$ & $\mathrm{MCB}_{2015}$ \\
\hline 2009 BL/GDP & 0.02 & $0.09^{* *}$ & $0.16^{* * *}$ & $0.19^{* * *}$ \\
& $(0.64)$ & $(2.34)$ & $(2.75)$ & $(3.05)$ \\
FD/GDP & $0.23^{* * *}$ & 0.02 & 0.04 & $-0.09^{* *}$ \\
& $(3.24)$ & $(0.35)$ & $(0.71)$ & $(-2.14)$ \\
FAI/GDP & $-0.03^{* *}$ & -0.00 & -0.01 & 0.02 \\
& $(-2.11)$ & $(-0.22)$ & $(-0.37)$ & $(1.52)$ \\
LS/FR & 0.04 & -0.01 & -0.01 & $-0.06^{* *}$ \\
& $(1.01)$ & $(-0.22)$ & $(-0.26)$ & $(-2.04)$ \\
$\Delta$ GDP & 0.08 & $0.14^{* *}$ & $0.24^{* * *}$ & $0.22^{* * *}$ \\
& $(1.56)$ & $(2.26)$ & $(4.23)$ & $(3.23)$ \\
Corruption index & 0.01 & $0.01^{* *}$ & 0.01 & 0.01 \\
& $(1.60)$ & $(2.12)$ & $(1.52)$ & $(1.27)$ \\
Constant & -0.01 & $-0.04^{* *}$ & $-0.04^{* *}$ & $-0.04^{* * *}$ \\
& $(1.55)$ & $(-2.33)$ & $(-2.27)$ & $(-3.05)$ \\
Observations & 30 & 30 & 30 & 30 \\
Adj. R ${ }^{2}$ & 0.56 & 0.48 & 0.46 & 0.50 \\
\hline
\end{tabular}




\section{Table 4: IV Estimation}

This table reports the results of IV regressions. EarlyTerm 09 is used as the instrumental variable for the 2009 abnormal new bank loan scaled by GDP. EarlyTerm 09 equals 1 if a province governor was in the first two years of his governor tenure as of 2009, and 0 otherwise. Panel A reports the results of the first-stage estimation. Panels B and $\mathrm{C}$ report the results of the year-by-year and panel second-stage estimations. For panel regressions, control variables include abnormal fiscal deficit (FD) scaled by GDP, abnormal fixed asset investment (FAI) scaled by GDP, abnormal local government land sale income (LS) scaled by fiscal revenue (FR), GDP growth, and the corruption index constructed by Ang et al. (2017). Heteroscedasticity-consistent $t$-statistics are reported in parentheses for Panels A and B. Heteroscedasticity-consistent $t$-statistics clustered by province and year are reported in parentheses for Panel C. ***, **, and * indicate significance at the $1 \%, 5 \%$, and $10 \%$ levels, respectively.

\begin{tabular}{lc}
\multicolumn{2}{l}{ Panel A: First-stage estimation } \\
\hline \multicolumn{2}{c}{$(1)$} \\
\hline EarlyTerm 09 & $-0.04^{* * *}$ \\
& $(-2.60)$ \\
Constant & $0.17^{* * *}$ \\
& $(16.09)$ \\
Observations & 30 \\
$\mathrm{R}^{2}$ & 0.12 \\
F-stat & 6.76 \\
p-value & 0.01 \\
\hline
\end{tabular}

Panel B: Second-stage year-by-year estimation

\begin{tabular}{lcccc}
\hline & $(1)$ & $(2)$ & $(3)$ & $(4)$ \\
& $\mathrm{MCB}_{2012}$ & $\mathrm{MCB}_{2013}$ & $\mathrm{MCB}_{2014}$ & $\mathrm{MCB}_{2015}$ \\
\hline $2009 B L / \hat{G} D P$ & $0.17^{*}$ & $0.18^{* *}$ & $0.28^{* *}$ & $0.33^{* *}$ \\
& $(1.71)$ & $(2.40)$ & $(2.38)$ & $(2.08)$ \\
Constant & -0.01 & -0.02 & -0.02 & -0.03 \\
& -0.78 & -1.26 & -0.96 & -1.17 \\
Observations & 30 & 30 & 30 & 30 \\
$\mathrm{R}^{2}$ & 0.09 & 0.29 & 0.29 & 0.16 \\
\hline
\end{tabular}


Table 4 continued

Panel C: Second-stage panel estimation

\begin{tabular}{lcccc}
\hline & $(1)$ & $(2)$ & $(3)$ & $(4)$ \\
\hline $2009 B L / \hat{G} D P$ & $0.24^{* *}$ & $0.21^{*}$ & $0.24^{* *}$ & 0.10 \\
& $(2.33)$ & $(1.78)$ & $(2.33)$ & $(1.07)$ \\
FD/GDP & & -0.00 & & 0.07 \\
& & $(-0.03)$ & & $(1.14)$ \\
FAI/GDP & & 0.01 & & -0.01 \\
& & $(0.95)$ & & $(-0.78)$ \\
LS/FR & & 0.01 & & -0.02 \\
& & $(0.28)$ & & $(-0.70)$ \\
$\Delta$ GDP & & 0.02 & & $0.16^{* * *}$ \\
& & $(0.46)$ & & $(4.14)$ \\
Corruption index & & $0.01^{* *}$ & & $0.01^{* *}$ \\
& & $(2.19)$ & & $(2.34)$ \\
Constant & -0.02 & $-0.04^{* * *}$ & -0.02 & $-0.04^{* * *}$ \\
& $(-1.13)$ & $(-2.81)$ & $(-1.42)$ & $(-3.08)$ \\
Year FE & No & No & Yes & Yes \\
Observations & 120 & 120 & 120 & 120 \\
$\mathrm{R}^{2}$ & 0.12 & 0.25 & 0.25 & 0.52 \\
\hline
\end{tabular}


Table 5: The Effects of 2009 Abnormal Bank Loan on Future Municipal Corporate Bond Issuance, Placebo Tests

This table reports the year-by-year regressions of 2012-2015 provincial municipal corporate bond (MCB) issuance in 2008 first-to-third-quarter bank loans. The dependent variable is the abnormal MCB issuance scaled by GDP in years 2012-2015 compared to the average value between 2004 and 2008. Annual MCB issuances at the provincial/regional level are aggregated over individual MCB bonds. The independent variable is the abnormal new bank loan scaled by GDP in 2008 Q1-Q3 compared to the average value between 2004 and 2007. Panel A reports the cross-provincial results of 2008 Q1-Q3 abnormal bank loan. Panel B reports the cross-provincial results of both 2009 and 2008 Q1-Q3 abnormal bank loans, where the $F$-stat and the associated $p$-values for the hypothesis of equal coefficients of 2009 bank loan and 2008Q1-Q3 bank loan are also reported. Data about bank loan are obtained from the $\mathrm{PBoC}$ and data about MCBs are obtained from WIND. Heteroscedasticity-consistent $t$-statistics are reported in parentheses. $* * *, * *$, and $*$ indicate significance at the $1 \%, 5 \%$, and $10 \%$ levels, respectively.

Panel A: 2008 Q1-Q3 bank loan and 2012-2015 MCB issuance

\begin{tabular}{lcccc}
\hline & $(1)$ & $(2)$ & $(3)$ & $(4)$ \\
& $\mathrm{MCB}_{2012}$ & $\mathrm{MCB}_{2013}$ & $\mathrm{MCB}_{2014}$ & $\mathrm{MCB}_{2015}$ \\
\hline 2008Q1-Q3 BL/GDP & 0.07 & -0.00 & -0.01 & -0.06 \\
& $(0.74)$ & $(-0.01)$ & $(-0.09)$ & $(-0.36)$ \\
Constant & $0.01^{* * *}$ & $0.02^{* *}$ & $0.03^{* * *}$ & $0.03^{* * *}$ \\
& $(5.02)$ & $(2.53)$ & $(3.86)$ & $(3.43)$ \\
Observations & 30 & 30 & 30 & 30 \\
Adj. R & -0.02 & -0.04 & -0.04 & -0.03 \\
\hline
\end{tabular}

Panel B: 2009 and 2008Q1-Q3 bank loan and 2012-2015 MCB issuance

\begin{tabular}{lcccc}
\hline & $(1)$ & $(2)$ & $(3)$ & $(4)$ \\
& $\mathrm{MCB}_{2012}$ & $\mathrm{MCB}_{2013}$ & $\mathrm{MCB}_{2014}$ & $\mathrm{MCB}_{2015}$ \\
\hline $2009 \mathrm{BL} / \mathrm{GDP}$ & $0.11^{*}$ & $0.15^{* * *}$ & $0.23^{* * *}$ & $0.18^{* * *}$ \\
& $(1.68)$ & $(2.73)$ & $(4.72)$ & $(2.74)$ \\
2008Q1-Q3 BL/GDP & 0.01 & -0.09 & -0.15 & -0.16 \\
& $(0.12)$ & $(-0.98)$ & $(-1.61)$ & $(-1.50)$ \\
Constant & -0.00 & -0.01 & -0.00 & 0.00 \\
& $(-0.14)$ & $(-0.92)$ & $(-0.40)$ & $(0.14)$ \\
$F$-test $\beta^{09}=\beta^{08 Q 1-Q 3}$ & $2.94^{*}$ & $3.20^{*}$ & $11.69^{* * *}$ & $6.08^{* *}$ \\
$p$-value & 0.10 & 0.08 & 0.00 & 0.02 \\
Observations & 30 & 30 & 30 & 30 \\
Adj. R & 0.07 & 0.34 & 0.38 & 0.24 \\
\hline
\end{tabular}


Table 6: The Effects of 2009 Abnormal Bank Loan on Future Municipal Corporate Bond Issuance, Panel Regressions

This table reports the panel regressions of 2012-2015 provincial municipal corporate bond (MCB) issuance on 2009 bank loan. The dependent variable is the abnormal MCB issuance scaled by GDP in years 2012-2015 compared to the average value between 2004 and 2008. Annual MCB issuances at the provincial level are aggregated over individual MCB bonds. The independent variable is the abnormal new bank loan scaled by GDP in 2009 compared to the average value between 2004 and 2008. Control variables include abnormal fiscal deficit (FD) scaled by GDP, abnormal fixed-asset investment (FAI) scaled by GDP, abnormal local government land sale income (LS) scaled by fiscal revenue (FR), GDP growth, and the corruption index constructed by Ang et al. (2016). MCB repay indicates the proceeds of MCB that are used to pay back bank loans. $\mathrm{MCB}_{\text {inv }}$ indicates the proceeds of $\mathrm{MCB}$ that are used for investment. $\mathrm{MCB}_{\text {other }}$ indicates the proceeds of $\mathrm{MCB}$ that are used for other purposes. $\mathrm{MCB}_{\text {repay }}^{10}$ includes those ten provinces with the most similar value of GDP in 2009, including Yunnan, Chongqing, Jilin, Shanxi, Tianjin, Jiangxi, Guangxi, Shan Xi, Heilongjiang, and Neimenggu. The denominator to scale $\mathrm{MCB}_{\text {repay }}^{10}$ in 2012-2015 is the 2009 GDP in each of those 10 provinces. Data about bank loan are obtained from the PBoC, data about MCBs are obtained from WIND, and data about control variables are obtained from the National Bureau of Statistics of China. Year fixed effects are included. Heteroscedasticity-consistent $t$-statistics clustered by province and year are reported in parentheses. $* * *, * *$, and $*$ indicate significance at the $1 \%, 5 \%$, and $10 \%$ levels, respectively.

\begin{tabular}{lcccccc}
\hline & $(1)$ & $(2)$ & $(3)$ & $(4)$ & $(5)$ & $(6)$ \\
& $\mathrm{MCB}$ & $\mathrm{MCB}$ & $\mathrm{MCB}_{\text {repay }}$ & $\mathrm{MCB}_{\text {inv }}$ & $\mathrm{MCB}_{\text {other }}$ & $\mathrm{MCB}_{\text {repay }}^{10}$ \\
\hline 2009 BL/GDP & $0.15^{* * *}$ & $0.10^{* *}$ & $0.04^{* *}$ & 0.01 & $0.02^{*}$ & $0.15^{* * *}$ \\
& $(3.45)$ & $(2.10)$ & $(1.97)$ & $(0.43)$ & $(1.89)$ & $(4.45)$ \\
FD/GDP & & 0.07 & 0.06 & 0.02 & $0.02^{* * *}$ & $-0.16^{* * *}$ \\
& & $(0.89)$ & $(1.47)$ & $(1.41)$ & $(3.31)$ & $(-3.67)$ \\
FAI/GDP & & -0.01 & $-0.01^{* *}$ & 0.00 & -0.00 & 0.00 \\
& & $(-0.65)$ & $(-2.17)$ & $(0.50)$ & $(-1.56)$ & $(0.08)$ \\
LS/FR & & -0.02 & -0.00 & -0.01 & 0.00 & 0.06 \\
& & $-0.68)$ & $(-0.31)$ & $(-1.02)$ & $(0.62)$ & $(1.21)$ \\
GDP growth & & $(3.57)$ & $(1.39)$ & $(4.99)$ & $(2.59)$ & $(2.57)$ \\
& & $0.01^{* * * *}$ & $0.01^{* * *}$ & 0.00 & 0.00 & $0.01^{* * *}$ \\
Corruption index & & $(3.17)$ & $(3.16)$ & $(0.90)$ & $(0.15)$ & $(4.12)$ \\
& & & 0.04 & $0.08^{* * *}$ & $0.01^{* * *}$ & $0.18^{* * *}$ \\
Constant & 0.00 & $-0.04^{* * *}$ & $-0.02^{* *}$ & $-0.01^{* *}$ & -0.00 & $-0.06^{* * *}$ \\
& $(1.13)$ & $(-2.98)$ & $(-2.52)$ & $(-2.23)$ & $(-1.55)$ & $(-3.05)$ \\
Year FE & Yes & Yes & Yes & Yes & Yes & Yes \\
Observations & 120 & 120 & 120 & 120 & 120 & 40 \\
Adj. R & 0.31 & 0.49 & 0.52 & 0.39 & 0.28 & 0.75 \\
\hline
\end{tabular}




\section{Table 7: The Effects of 2009 Loan Maturity on Future Municipal Corporate}

Bond Issuance

This table reports the year-by-year and panel regressions of 2012-2015 provincial municipal corporate bond (MCB) issuance on 2009 bank loan and the cross-term with LGFV loan fraction of China Development Bank (CDB). The dependent variable is the abnormal MCB issuance scaled by GDP in years 2012-2015 compared to the average value between 2004 and 2008. Annual MCB issuances at the provincial level are aggregated over individual MCB bonds. The independent variable is the abnormal new bank loan scaled by GDP in 2009 compared to the average value between 2004 and 2008, the fraction of the LGFV loan from CDB in 2009, and the cross-term of the two variables. Data about bank loans are obtained from the $\mathrm{PBoC}$, data about MCBs are obtained from WIND, and the data about the CDB LGFV loan fraction are from Gao et al. (2018). Heteroscedasticity-consistent $t$-statistics are reported in parentheses for regressions (1) and (4). Heteroscedasticity-consistent $t$-statistics clustered by province and year are reported in parentheses for regression (5). ${ }^{* * *}, * *$, and $*$ indicate significance at the $1 \%$, $5 \%$, and $10 \%$ levels, respectively.

\begin{tabular}{lccccc}
\hline & $(1)$ & $(2)$ & $(3)$ & $(4)$ & $(5)$ \\
& $\mathrm{MCB}_{2012}$ & $\mathrm{MCB}_{2013}$ & $\mathrm{MCB}_{2014}$ & $\mathrm{MCB}_{2015}$ & $\mathrm{MCB}_{\text {panel }}$ \\
\hline 2009 BL/GDP & $0.19^{* * *}$ & $0.22^{* * *}$ & $0.37^{* * *}$ & $0.40^{* * *}$ & $0.29^{* * *}$ \\
& $(3.20)$ & $(3.04)$ & $(5.36)$ & $(4.98)$ & $(4.83)$ \\
2009 CDB LGFV \% & 0.06 & $0.06^{* *}$ & $0.11^{* * *}$ & $0.17^{* * *}$ & $0.10^{* * *}$ \\
& $(1.09)$ & $(2.19)$ & $(2.57)$ & $(3.26)$ & $(2.73)$ \\
BL/GDP * CDB LGFV \% & -0.33 & $-0.36^{* *}$ & $-0.67^{* * *}$ & $-0.98^{* * *}$ & $-0.58^{* * *}$ \\
& $(-1.04)$ & $(-2.22)$ & $(-3.24)$ & $(-4.07)$ & $(-2.96)$ \\
Constant & -0.02 & $-0.02^{*}$ & $-0.03^{* *}$ & $-0.04^{* * *}$ & $-0.03^{* * *}$ \\
& $(-1.56)$ & $(-1.94)$ & $(-2.39)$ & $(-2.63)$ & $(-2.88)$ \\
Year FE & No & No & No & No & Yes \\
Observations & 30 & 30 & 30 & 30 & 120 \\
Adj. R ${ }^{2}$ & 0.08 & 0.37 & 0.47 & 0.48 & 0.43 \\
\hline
\end{tabular}


Table 8: The Effects of 2009 Abnormal Bank Loan on Municipal Corporate Bond Excess Yield Spread

This table reports the regressions of 2012-2015 municipal corporate bond (MCB) excess issuing spread on 2009 bank loan. The dependent variable is the amount-weighted spread of the MCB-issuance rate over the yield of China Development Bank bond with the same maturity for each year and province. The independent variable is the abnormal new bank loan scaled by GDP in 2009 compared to the average value between 2004 and 2008. Control variables include bond rating, bond maturity, abnormal fiscal deficit (FD) scaled by GDP, abnormal fixed-asset investment (FAI) scaled by GDP, abnormal local government land sale income (LS) scaled by fiscal revenue (FR), and GDP growth. Data about bank loan are obtained from the the PBoC, data about MCBs are obtained from WIND, and data about control variables are obtained from the National Bureau of Statistics of China. Heteroscedasticity-consistent $t$-statistics clustered by province and year are reported in parentheses for regressions (1) and (2). Heteroscedasticity-consistent $t$-statistics are reported in parentheses for regressions (3) and (6). ***, **, and $*$ indicate significance at the $1 \%, 5 \%$, and $10 \%$ levels, respectively.

\begin{tabular}{lcccccc}
\hline & $(1)$ & $(2)$ & $(3)$ & $(4)$ & $(5)$ & $(6)$ \\
& Spread & Spread & Spread $_{2012}$ & Spread $_{2013}$ & Spread $_{2014}$ & Spread $_{2015}$ \\
\hline 2009 BL/GDP & & -0.80 & -1.79 & -1.30 & -0.08 & -1.01 \\
Rating & & $(-1.40)$ & $(-1.26)$ & $(-1.63)$ & $(-0.12)$ & $(-0.83)$ \\
& $0.64^{* * *}$ & $0.61^{* * *}$ & $0.54^{* * *}$ & $0.30^{* * *}$ & $0.79^{* * *}$ & $0.84^{* * *}$ \\
Maturity & $(4.84)$ & $(4.30)$ & $(3.92)$ & $(2.82)$ & $(5.81)$ & $(4.22)$ \\
& 0.03 & 0.02 & 0.04 & 0.03 & 0.01 & -0.02 \\
FD/GDP & $(0.74)$ & $(0.76)$ & $(0.60)$ & $(0.93)$ & $(0.16)$ & $(-0.71)$ \\
& $-1.22^{*}$ & -0.91 & -1.29 & -0.31 & -1.06 & $-3.35^{* *}$ \\
FAI/GDP & $(-1.67)$ & $(-1.24)$ & $(-1.23)$ & $(-0.28)$ & $(-0.91)$ & $(-2.50)$ \\
& $0.54^{* * *}$ & $0.51^{* *}$ & 0.68 & $0.85^{* * *}$ & $0.52^{*}$ & 0.57 \\
LS/FR & $(2.83)$ & $(2.53)$ & $(1.25)$ & $(3.07)$ & $(1.91)$ & $(1.45)$ \\
& $-1.00^{* *}$ & $-1.02^{* *}$ & $-1.74^{*}$ & -1.08 & -0.77 & -0.44 \\
GDP growth & $-2.31)$ & $(-2.29)$ & $(-1.64)$ & $(-1.25)$ & $(-1.52)$ & $(-0.33)$ \\
& -1.31 & -1.21 & 0.42 & -2.10 & -0.70 & -3.83 \\
Corruption index & $0.15^{* *}$ & $0.17^{* *}$ & $0.22^{*}$ & 0.01 & 0.11 & $0.36^{* *}$ \\
& $(2.12)$ & $(2.10)$ & $(1.76)$ & $(0.09)$ & $(1.28)$ & $(2.12)$ \\
Constant & $0.68^{* *}$ & $0.83^{* *}$ & 0.69 & $1.19^{* *}$ & -0.14 & -0.33 \\
& $(2.02)$ & $(2.45)$ & $(1.20)$ & $(2.02)$ & $(-0.56)$ & $(-0.55)$ \\
Year FE & Yes & Yes & No & No & No & No \\
Observations & 117 & 117 & 28 & 30 & 30 & 29 \\
Adj. R ${ }^{2}$ & 0.79 & 0.79 & 0.74 & 0.62 & 0.76 & 0.60 \\
\hline
\end{tabular}




\section{Table 9: The Effects of 2009 Abnormal Bank Loan on Future New Entrust}

\section{Loans}

This table reports the regression results of new entrusted loans (EL) and abnormal bank loans (BL) on the 2009 abnormal bank loan. The dependent variable is the new entrusted loans scaled by GDP in years 2013-2015 for columns (1)-(5) and abnormal new bank loans scaled by GDP in years 2012-2015 for column (6). The independent variable is the abnormal new bank loan scaled by GDP in 2009 compared to the average value between 2004 and 2008. Control variables include abnormal fiscal deficit (FD) scaled by GDP, abnormal fixed-asset investment (FAI) scaled by GDP, abnormal local government land sale income (LS) scaled by fiscal revenue (FR), and GDP growth. Results of year-by-year and panel regressions are reported. Data about bank loans and entrusted loans are obtained from the $\mathrm{PBoC}$ and data about control variables are obtained from the National Bureau of Statistics of China. Heteroscedasticity-consistent $t$-statistics are reported in parentheses for regressions (1) and (3). Heteroscedasticityconsistent $t$-statistics clustered by province and year are reported in parentheses for regressions (4) and (6).***, **, and * indicate significance at the $1 \%, 5 \%$, and $10 \%$ levels, respectively.

\begin{tabular}{|c|c|c|c|c|c|c|}
\hline & $\begin{array}{c}(1) \\
\mathrm{EL}_{2013}\end{array}$ & $\begin{array}{c}(2) \\
\mathrm{EL}_{2014}\end{array}$ & $\begin{array}{c}(3) \\
\mathrm{EL}_{2015}\end{array}$ & $\begin{array}{c}(4) \\
\text { EL }_{\text {panel }}\end{array}$ & $\begin{array}{c}(5) \\
\mathrm{EL}_{\text {panel }}\end{array}$ & $\begin{array}{c}(6) \\
\mathrm{BL}_{\text {panel }}\end{array}$ \\
\hline 2009 BL/GDP & $\begin{array}{l}0.20^{* *} \\
(2.00)\end{array}$ & $\begin{array}{l}0.23^{* *} \\
(2.08)\end{array}$ & $\begin{array}{c}0.14 \\
(1.37)\end{array}$ & $\begin{array}{l}0.19^{* *} \\
(2.35)\end{array}$ & $\begin{array}{l}0.20^{* *} \\
(2.54)\end{array}$ & $\begin{array}{c}-0.00 \\
(-0.03)\end{array}$ \\
\hline FD/GDP & & & & & $\begin{array}{c}-0.04 \\
(-0.48)\end{array}$ & $\begin{array}{c}0.79^{* * *} \\
(5.33)\end{array}$ \\
\hline FAI/GDP & & & & & $\begin{array}{l}-0.05^{*} \\
(-1.79)\end{array}$ & $\begin{array}{l}0.12^{* *} \\
(2.44)\end{array}$ \\
\hline $\mathrm{LS} / \mathrm{FR}$ & & & & & $\begin{array}{c}0.01 \\
(0.26)\end{array}$ & $\begin{array}{c}0.00 \\
(0.00)\end{array}$ \\
\hline$\Delta \mathrm{GDP}$ & & & & & $\begin{array}{c}0.10 \\
(0.68)\end{array}$ & $\begin{array}{c}-0.25 \\
(-1.46)\end{array}$ \\
\hline Constant & $\begin{array}{c}0.01 \\
(0.41)\end{array}$ & $\begin{array}{c}-0.00 \\
(-0.25)\end{array}$ & $\begin{array}{c}0.00 \\
(0.16)\end{array}$ & $\begin{array}{c}0.00 \\
(0.68)\end{array}$ & $\begin{array}{c}0.01 \\
(0.83)\end{array}$ & $\begin{array}{c}0.01 \\
(0.42)\end{array}$ \\
\hline Year FE & No & No & No & Yes & Yes & Yes \\
\hline Observations & 30 & 30 & 30 & 90 & 90 & 120 \\
\hline Adj. $R^{2}$ & 0.13 & 0.14 & 0.04 & 0.14 & 0.27 & 0.60 \\
\hline
\end{tabular}




\section{For Online Publication: Appendix}

This Internet Appendix consists of four sections. In Section A, we describe how we estimate the sector-level abnormal bank loans extended in 2009. In Section B, we provide data-construction details of total local government debt balance and its four major components. In Section C, we describe how we estimate the investment of wealth management products in municipal corporate bonds. In Section D, additional results are presented.

\section{A Estimates of Sector-Level Abnormal Bank Loans in 2009}

We estimate that the 2009 stimulus caused RMB 4.7 trillion extra bank loans to the entire Chinese economy, among which, about 2.3 trillion went to LGFVs, about RMB 1 trillion went to the non-residential sector (but excluding LGFVs), and the remaining RMB 1.4 trillion went to the residential sector. Note that the estimated abnormal LGFV bank loans (i.e., 2.3 trillion) square well with Gao et al. (2018), who have detailed loanlevel information for LGFVs from the largest 19 banks (18 commercial banks and China Development Bank) in 2009. Finally, with the help of the data in Gao et al. (2018), we estimate that for the RMB 2.3 trillion in bank loans to LGFVs, RMB 2.06 trillion came from commercial banks and RMB 0.24 trillion came from policy banks.

The detailed steps to construct the above estimates are as follows. First, the total abnormal new bank loans (RMB 4.7 trillion) is the difference between the actual 2009 new bank loan (9.6 trillion) and the estimated 2009 normal new bank loans (RMB 4.9 trillion, based on the average BL/GDP ratio in 2004-2008). Following the same approach, the 2009 abnormal new non-residential bank loan is estimated at RMB 3.3 trillion, implying an abnormal residential new bank loan of RMB 1.4 trillion (4.7-3.3). Second, we decompose this RMB 3.3 trillion number further into LGFVs and the rest. To this end, we estimate the 2009 normal new bank loan to LGFVs to be RMB 0.75 trillion (the ratio of LGFV new bank loan over new bank loan in 2008 multiplied by the estimated 2009 normal new bank loan; the 2008 LGFV new bank loan is based on the 2010 national audit report and WIND). Taking this number out of the 2009 actual LGFV bank loan 3.05 trillion (Bai et al. (2016), p.14), we estimate the 2009 abnormal 
LGFV bank loan to be RMB 2.3 trillion (3.05-0.75), which then leaves the 2009 abnormal non-residential (excluding LGFV) new bank loan to be 1 trillion (3.3-2.3).

\section{B Construction of Local Government Debt Balance}

\section{B.1 Total local government debt balance}

1. The numbers as of the end of 2010, 2012, and $2013 \mathrm{H} 1$ are provided by two auditing reports (2011 and 2013) on local government debt issued by the National Audit Office (NAO).

2. The numbers as of the end of 2008 and 2009 are calculated according to local government debt growth given in Figure 2 of the 2011 NAO report.

3. The number as of the end of 2014 is from the proposal to the State of Council submitted by the Ministry of Finance (MOF), which says that by the end of 2014, the local governments' full obligation was RMB 15.4 trillion and the total local government guaranteed/contingent liability was RMB 8.6 trillion.

4. The numbers as of the end of 2015/2016 are calculated according to the 2015/2016 local government full obligation of RMB 16/17.1 trillion and the 2014 fraction of the local governments' full obligation as the total local government debt.

5. The numbers as of the end of 2011 and 2013 are interpolated assuming the growth rate of local government debt to be constant between 2010 and 2012, and between 2012 and 2014.

\section{B.2 Local government bank loan balance}

1. The numbers as of the end of 2010 and June 2013 are from the two NAO reports.

2. The numbers as of the end of 2008, 2009, 2011, and 2012 are adjusted from the local government financing vehicle (LGFV) bank loan balance data available from WIND.

(a) The ratio between the average 2010 and June 2013 local government bank loan balance from the NAO reports, and the average 2010 and June 2013 LGFV bank loan balance is used as the adjustment factor. 
(b) LGFV bank loan balance data are from WIND as of the end of 2008, 2009, and 2012.

(c) The LGFV bank loan balance as of the end of 2011 is interpolated, assuming the growth rate between 2010 and 2012 to be constant.

3. The numbers as of the end of 2013, 2014, 2015, and 2016 are adjusted from the LGFV bank loan balance estimated using China Construction Bank's (CCB) LGFV balance.

(a) The country-wide LGFV bank loan balance in the commercial bank measurement as of the end of 2013-2016 is estimated using CCB's LGFV bank loan balance and CCB's bank loan balance share as of all commercial banks.

(b) The growth rates of the country-wide LGFV bank loan balance in the commercial bank measurement are used to estimate the LGFV bank loan balance in the WIND measurement from 2013 to 2016.

(c) The numbers of the local government bank loan balance as of the end of 20132016 are estimated from section 3(b) LGFV bank loan balance adjusted by section 2(a) adjustment factor.

\section{B.3 Municipal corporate bond balance}

1. Individual municipal corporate bonds, both outstanding and matured, are aggregated over their corresponding outstanding periods to calculate the MCB balance as of the end of each year.

\section{B.4 Municipal bond balance}

1. Individual municipal bonds, both outstanding and matured, are aggregated over their corresponding outstanding periods to calculate the municipal bond balance as of the end of each year.

\section{B.5 Local government trust financing balance}

Municipality-Trust cooperation balance data are reported officially by China Trustee Association. We assume that the fraction of Municipality-Trust cooperation over total Trust loans remains constant over years.

1. Quarterly Municipality-Trust cooperation balance data are available since 2010 . 
2. As of June 30, 2013, the NAO report shows that the total local government trust financing balance is RMB 1.43 trillion and the Municipality-Trust cooperation balance is RMB 0.8 trillion. The adjustment factor is therefore $1.43 / 0.8=1.77$.

3. The numbers of Municipality-Trust cooperation balance as of the end of 2010-2016 are multiplied by 1.77 to reflect the total local government trust financing balance.

\section{Construction of Wealth Management Product In- vestment in Municipal Corporate Bonds}

1. Total MCB balance by rating (AAA, AA+, AA, and $\leq \mathrm{AA}$ ) is aggregated from individual MCBs using bonds rating at issuance. If a bond does not have rating information at issuance, we use its issuer's rating at issuance as a proxy. Only 1.57\% of $\mathrm{MCB}$ in terms of RMB issuance value do not have any rating information.

2. Total credit bond balance by rating (AAA, $\mathrm{AA}+, \mathrm{AA}$, and $\leq \mathrm{AA})$ is from China Central Depository and Clearing Corporation, downloaded from WIND.

3. Credit bond balance by rating ( $\mathrm{AAA}, \mathrm{AA}+, \mathrm{AA}$, and $\leq \mathrm{AA}$ ) held by WMPs is from China Commercial Bank Wealth Management Products Annual Reports issued by China Banking Wealth Management Registration System.

4. Fractions of credit bond balance held by WMPs by rating are calculated from numbers in 2 and 3.

5. Assuming that WMPs hold MCBs with the same percentage as WMPs hold all credit bonds, we estimate the MCB balance held by WMPs from numbers in 1 and 4 . 


\section{Additional Results}

Table A.1: Summary Statistics of Municipal Corporate Bond Issuance

This table reports the summary statistics of municipal corporate bond (MCB) issuance. Panels A and B report MCB issuance number, issuance amount (billion RMB), and issuance amount by purpose (repayment of existing bank loan, investment, and other)

for 7 regions and 30 provinces, respectively. Total issuance amount is greater than the sum of three purposes because only about $80 \%$ of MCBs are with disclosure.

\begin{tabular}{lccccc} 
Panel A: MCB Issuance by Region & & \\
\hline Province & $\begin{array}{c}\text { Number } \\
\text { of Bonds }\end{array}$ & $\begin{array}{c}\text { Amount } \\
\text { (total) }\end{array}$ & $\begin{array}{c}\text { Amount } \\
\text { (repay) }\end{array}$ & $\begin{array}{c}\text { Amount } \\
\text { (inv) }\end{array}$ & $\begin{array}{c}\text { Amount } \\
\text { (other) }\end{array}$ \\
\hline Center China & 554 & 635.9 & 109.7 & 371.8 & 6.4 \\
East China & 2428 & 2272.9 & 610.0 & 1268.7 & 54.1 \\
North China & 630 & 1004.7 & 234.5 & 493.3 & 26.8 \\
South China & 404 & 448.0 & 138.5 & 258.4 & 6.2 \\
Northeast & 245 & 292.5 & 48.0 & 193.8 & 1.9 \\
Northwest & 393 & 428.3 & 101.4 & 205.2 & 4.3 \\
Southwest & 800 & 845.1 & 235.4 & 449.9 & 16.5 \\
\hline Total & 5454 & 5927.3 & 1477.5 & 3241.2 & 116.1 \\
\hline
\end{tabular}


Panel B: MCB Issuance by Province

\begin{tabular}{lccccc}
\hline Province & $\begin{array}{c}\text { Number } \\
\text { of Bonds }\end{array}$ & $\begin{array}{c}\text { Amount } \\
\text { (total) }\end{array}$ & $\begin{array}{c}\text { Amount } \\
\text { (repay) }\end{array}$ & $\begin{array}{c}\text { Amount } \\
\text { (inv) }\end{array}$ & $\begin{array}{c}\text { Amount } \\
\text { (other) }\end{array}$ \\
\hline Anhui & 206 & 218.7 & 55.6 & 131.6 & 5.1 \\
Beijing & 210 & 368.0 & 99.5 & 201.2 & 4.9 \\
Chongqing & 265 & 287.8 & 87.2 & 147.4 & 6.0 \\
Fujian & 293 & 244.3 & 93.3 & 114.7 & 9.3 \\
Gansu & 78 & 97.6 & 21.4 & 44.3 & 3.0 \\
Guangdong & 232 & 303.2 & 114.6 & 168.1 & 2.7 \\
Guangxi & 165 & 135.6 & 23.0 & 82.0 & 3.5 \\
Guizhou & 89 & 118.1 & 17.2 & 85.8 & 1.5 \\
Hainan & 7 & 9.2 & 0.9 & 8.3 & 0.0 \\
Hebei & 93 & 98.4 & 12.1 & 67.1 & 2.4 \\
Heilongjiang & 58 & 61.4 & 3.6 & 51.7 & 0.0 \\
Henan & 143 & 156.3 & 30.1 & 78.9 & 0.4 \\
Hubei & 198 & 204.7 & 35.9 & 117.8 & 0.2 \\
Hunan & 213 & 274.9 & 43.7 & 175.1 & 5.8 \\
Jiangsu & 997 & 859.0 & 203.5 & 447.9 & 17.0 \\
Jiangxi & 136 & 140.2 & 29.8 & 95.0 & 2.9 \\
Jilin & 36 & 42.9 & 14.0 & 18.7 & 0.5 \\
Liaoning & 151 & 188.2 & 30.4 & 123.5 & 1.4 \\
Neimenggu & 64 & 70.5 & 6.9 & 54.3 & 0.0 \\
Ningxia & 9 & 12.1 & 0.5 & 11.6 & 0.0 \\
Qinghai & 36 & 44.9 & 23.7 & 15.2 & 0.0 \\
Shan_xi & 149 & 176.4 & 41.3 & 69.9 & 0.9 \\
Shandong & 251 & 273.3 & 75.0 & 158.0 & 9.2 \\
Shanghai & 165 & 202.3 & 83.1 & 95.1 & 3.3 \\
Shanxi & 51 & 67.7 & 5.2 & 38.0 & 1.5 \\
Sichuan & 275 & 265.5 & 87.3 & 133.2 & 3.7 \\
Tianjin & 212 & 400.0 & 110.7 & 132.8 & 18.0 \\
Xinjiang & 121 & 97.4 & 14.5 & 64.2 & 0.4 \\
Yunnan & 171 & 173.7 & 43.7 & 83.5 & 5.2 \\
Zhejiang & 380 & 335.0 & 69.8 & 226.3 & 7.2 \\
\hline
\end{tabular}




\section{Table A.2: The Effects of 2009 Abnormal Bank Loan on Future Municipal Corporate Bonds Net Issuance, Year-by-Year Regressions}

This table reports the year-by-year regressions of 2012-2015 MCB issuance on 2009 bank loan. The dependent variable is the abnormal MCB issuance scaled by GDP in years 2012-2015 compared to the average value between 2004 and 2008. Annual MCB issuance at the regional and provincial levels is aggregated over individual MCB bonds. The independent variable is the abnormal new bank loan scaled by GDP in 2009 compared to the average value between 2004 and 2008. Panel A and Panel B report the regional and provincial results, respectively. Data about bank loans are obtained from the PBoC and data about MCBs are obtained from WIND. Heteroscedasticity-consistent $t$-statistics are reported in parentheses. $* * *, * *$, and $*$ indicate significance at the $1 \%, 5 \%$, and $10 \%$ levels, respectively.

Panel A: 2009 bank loan and 2012-2015 MCB net issuance, regional

\begin{tabular}{lcccc}
\hline & $(1)$ & $(2)$ & $(3)$ & $(4)$ \\
& $\mathrm{MCB}_{2012}^{\text {net }}$ & $\mathrm{MCB}_{2013}^{\text {net }}$ & $\mathrm{MCB}_{2014}^{\text {net }}$ & $\mathrm{MCB}_{2015}^{\text {net }}$ \\
\hline 2009 BL/GDP & $0.11^{* * *}$ & $0.11^{* *}$ & $0.21^{* * *}$ & $0.18^{*}$ \\
& $(2.66)$ & $(2.24)$ & $(3.20)$ & $(1.66)$ \\
Constant & -0.00 & -0.00 & -0.01 & -0.01 \\
& $(-0.46)$ & $(-0.47)$ & $(-0.64)$ & $(-0.79)$ \\
Observations & 7 & 7 & 7 & 7 \\
Adj. R & 0.42 & 0.35 & 0.47 & 0.31 \\
\hline
\end{tabular}

Panel B: 2009 bank loan and 2012-2015 MCB net issuance, provincial

\begin{tabular}{lcccc}
\hline & $(1)$ & $(2)$ & $(3)$ & $(4)$ \\
& $\mathrm{MCB}_{2012}^{\text {net }}$ & $\mathrm{MCB}_{2013}^{\text {net }}$ & $\mathrm{MCB}_{2014}^{\text {net }}$ & $\mathrm{MCB}_{2015}^{\text {net }}$ \\
\hline 2009 BL/GDP & 0.11 & $0.13^{* * *}$ & $0.18^{* * *}$ & 0.08 \\
& $(1.55)$ & $(2.61)$ & $(3.65)$ & $(1.54)$ \\
Constant & -0.00 & -0.01 & -0.00 & 0.00 \\
& $(-0.15)$ & $(-0.89)$ & $(-0.45)$ & $(0.52)$ \\
Observations & 30 & 30 & 30 & 30 \\
Adj. R & 0.10 & 0.31 & 0.33 & 0.06 \\
\hline
\end{tabular}




\section{Table A.3: The Effects of 2009 Abnormal LGFV Loan on Future Municipal Corporate Bond Issuance, Year-by-Year Regressions}

This table reports the year-by-year regressions of 2012-2015 provincial municipal corporate bond (MCB) issuance on $2009 \mathrm{LGFV}$ loan. The dependent variable is the abnormal MCB issuance scaled by GDP in years 2012-2015 compared to the average value between 2004 and 2008. Annual MCB issuance at the provincial/regional level is aggregated over individual MCB bonds. The independent variable is the abnormal new LGFV bank loans scaled by GDP in 2009 compared to the average value between 2007 and 2008. Control variables include abnormal fiscal deficit (FD) scaled by GDP, abnormal fixed-asset investment (FAI) scaled by GDP, abnormal local government land sale income (LS) scaled by fiscal revenue (FR), GDP growth, and the corruption index constructed by Ang et al. (2017). Data about LGFV bank loans are from Gao et al. (2018), data about MCBs are obtained from WIND, and data about control variables are obtained from the National Bureau of Statistics of China. Heteroscedasticity-consistent $t$-statistics are reported in parentheses. $* * *, * *$, and $*$ indicate significance at the $1 \%, 5 \%$, and $10 \%$ levels, respectively.

\begin{tabular}{lcccc}
\hline & $(1)$ & $(2)$ & $(3)$ & $(4)$ \\
& $\mathrm{MCB}_{2012}$ & $\mathrm{MCB}_{2013}$ & $\mathrm{MCB}_{2014}$ & $\mathrm{MCB}_{2015}$ \\
\hline 2009 LGFVBL/GDP & 0.03 & $0.11^{* *}$ & $0.25^{* * *}$ & $0.27^{* * *}$ \\
& $(0.51)$ & $(2.00)$ & $(3.53)$ & $(3.21)$ \\
FD/GDP & $0.24^{* * *}$ & $0.09^{*}$ & $0.15^{* * *}$ & 0.03 \\
& $(3.62)$ & $(1.74)$ & $(3.82)$ & $(0.59)$ \\
FAI/GDP & $-0.03^{* *}$ & -0.01 & -0.01 & 0.01 \\
& $(-2.07)$ & $(-0.71)$ & $(-0.73)$ & $(0.95)$ \\
LS/FR & 0.03 & -0.05 & -0.02 & $-0.06^{* *}$ \\
& $(0.92)$ & $(-0.94)$ & $(-0.62)$ & $(-2.43)$ \\
$\Delta$ GDP & 0.07 & $0.12^{*}$ & $0.27^{* * *}$ & $0.22^{* * *}$ \\
& $(1.53)$ & $(1.87)$ & $(4.33)$ & $(3.00)$ \\
Corruption index & 0.01 & 0.01 & 0.00 & 0.00 \\
& $(1.18)$ & $(1.26)$ & $(0.33)$ & $(0.29)$ \\
Constant & -0.01 & -0.02 & -0.02 & -0.02 \\
& $(-0.90)$ & $(-1.44)$ & $(-0.92)$ & $(-0.85)$ \\
Observations & 30 & 30 & 30 & 30 \\
Adj. R & 0.56 & 0.43 & 0.46 & 0.43 \\
\hline
\end{tabular}




\section{Table A.4: The Effects of 2009 Abnormal LGFV Loan on Future Municipal Corporate Bond Issuance, Panel Regressions}

This table reports the panel regressions of 2012-2015 provincial municipal corporate bond (MCB) issuance on 2009 LGFV loan. The dependent variable is the abnormal MCB issuance scaled by GDP in years 2012-2015 compared to the average value between 2004 and 2008. Annual MCB issuances at the provincial level are aggregated over individual MCB bonds. The independent variable is the abnormal new LGFV bank loans scaled by GDP in 2009 compared to the average value between 2007 and 2008. Control variables include abnormal fiscal deficit (FD) scaled by GDP, abnormal fixed-asset investment (FAI) scaled by GDP, abnormal local government land sale income (LS) scaled by fiscal revenue (FR), GDP growth, and the corruption index constructed by Ang et al. (2017). $\mathrm{MCB}_{\text {repay }}$ indicates the proceeds of MCBs that are used to pay back bank loans. $\mathrm{MCB}_{\text {inv }}$ indicates the proceeds of MCBs that are used for investment. $\mathrm{MCB}_{\text {other }}$ indicates the proceeds of MCBs that are used for other purposes. MCB 10 repay includes those 10 provinces with the most similar value of GDP in 2009, including Yunnan, Chongqing, Jilin, Shanxi, Tianjin, Jiangxi, Guangxi, Shan Xi, Heilongjiang, and Neimenggu. The denominator to scale $\mathrm{MCB}_{\text {repay }}^{10}$ in 2012-2015 is the 2009 GDP in each of those 10 provinces. Data about LGFV bank loans are from Gao et al. (2018), data about MCBs are obtained from WIND, and data about control variables are obtained from the National Bureau of Statistics of China. Year fixed effects are included. Heteroscedasticity-consistent $t$-statistics clustered by province and year are reported in parentheses. ${ }^{* * *}, * *$, and ${ }^{*}$ indicate significance at the $1 \%, 5 \%$, and $10 \%$ levels, respectively.

\begin{tabular}{lcccccc}
\hline & $(1)$ & $(2)$ & $(3)$ & $(4)$ & $(5)$ & $(6)$ \\
& $\mathrm{MCB}$ & $\mathrm{MCB}$ & $\mathrm{MCB}_{\text {repay }}$ & $\mathrm{MCB}_{\text {inv }}$ & $\mathrm{MCB}_{\text {other }}$ & $\mathrm{MCB}_{\text {repay }}^{10}$ \\
\hline 2009 LGFVBL/GDP & $0.17^{* *}$ & $0.15^{* *}$ & 0.05 & 0.02 & 0.03 & $0.15^{* * *}$ \\
& $(2.28)$ & $(2.08)$ & $(1.56)$ & $(0.91)$ & $(1.54)$ & $(3.01)$ \\
FD/GDP & & $0.13^{* * *}$ & $0.08^{* *}$ & $0.02^{* * *}$ & $0.03^{* * *}$ & $-0.18^{* *}$ \\
& & $(2.57)$ & $(2.43)$ & $(3.20)$ & $(7.88)$ & $(-2.18)$ \\
FAI/GDP & & -0.01 & $-0.01^{* *}$ & 0.00 & -0.00 & $0.03^{* *}$ \\
& & $(-0.82)$ & $(-2.29)$ & $(0.57)$ & $(-1.65)$ & $(2.32)$ \\
LS/FR & & -0.03 & -0.00 & -0.01 & 0.00 & 0.02 \\
& & $-1.15)$ & $(-0.61)$ & $(-1.18)$ & $(0.44)$ & $(0.57)$ \\
GDP growth & & $(2.86)$ & $(1.29)$ & $(4.66)$ & $(1.91)$ & $(3.40)$ \\
& & 0.01 & $0.00^{* *}$ & 0.00 & -0.00 & $0.01^{*}$ \\
Corruption index & & $(1.37)$ & $(2.32)$ & $(0.47)$ & $(-0.65)$ & $(1.81)$ \\
& 0.01 & $-0.03^{* *}$ & $-0.02^{* *}$ & -0.00 & 0.00 & $-0.07^{* * *}$ \\
Constant & $(1.07)$ & $(-2.31)$ & $(-2.15)$ & $(-1.51)$ & $(0.18)$ & $(-4.17)$ \\
& Yes & Yes & Yes & Yes & Yes & Yes \\
Year FE & 120 & 120 & 120 & 120 & 120 & 40 \\
Observations & 0.23 & 0.47 & 0.49 & 0.40 & 0.28 & 0.67 \\
Adj. R ${ }^{2}$ & & & & & & $0.01 *$ \\
\hline
\end{tabular}

